\title{
RESEARCH
}

Open Access

\section{Characterization of a novel HDAC/RXR/ HtrA1 signaling axis as a novel target to overcome cisplatin resistance in human non-small cell lung cancer}

Wenjing Wang ${ }^{1,2+}$, Mengyue Zhao ${ }^{1,2+}$, Lijuan Cui ${ }^{1,2+}$, Yong Ren ${ }^{3}$, Jingyuan Zhang ${ }^{1,2}$, Junli Chen ${ }^{1,2}$, Lina Jia ${ }^{1,2}$, Jiayu Zhang ${ }^{1,2}$, Jingyu Yang ${ }^{1,2}$, Guoliang Chen ${ }^{4}$, Charles R. Ashby Jr ${ }^{5}$, Chunfu Wu ${ }^{1,2^{*}}$, Zhe-Sheng Chen ${ }^{5^{*}}$ (I) and Lihui Wang ${ }^{1,2^{*}}$

\begin{abstract}
Background: Cisplatin is a first-line drug for the treatment of human non-small cell lung cancer (NSCLC); however, the majority of patients will develop drug resistance after treatment. In order to overcome cisplatin resistance, it is important to understand the mechanisms underlying the resistance.

Methods: A gene microarray was used to screen for genes related to cisplatin resistance in NSCLC cell lines. Subsequently, the correlation between the HDAC, RXR and HtrA1 genes, in NSCLC, were verified using gene manipulation. Immunohistochemical staining was used to detect HDAC, RXR and HtrA1 expression in NSCLC specimens. Proliferation, migration and invasion assays were performed in vitro and in vivo to determine the role of the HDAC/RXR/HtrA1 signaling axis in cisplatin resistance, and luciferase reporter analysis and ChIP assays were performed to ascertain the mechanisms by which HDAC and RXR regulate the expression of HtrA1. Furthermore, in vitro and in vivo experiments were conducted in NSCLC cisplatin-resistant NSCLC to elucidate the effect of the low molecular weight compound, DW22, which targets the NSCLC cisplatin resistance HDAC/RXR/HtrA1 signaling pathway.

(Continued on next page)
\end{abstract}

\footnotetext{
*Correspondence: wucf@syphu.edu.cn; chenz@stjohns.edu;

Ihwang@syphu.edu.cn

†Wenjing Wang, Mengyue Zhao and Lijuan Cui contributed equally to this

work.

'Department of Pharmacology, Shenyang Pharmaceutical University,

Shenyang, PR China

${ }^{5}$ Department of Pharmaceutical Sciences, College of Pharmacy and Health

Sciences, St. John's University, Newyork, NY 11439, USA

Full list of author information is available at the end of the article
}

(c) The Author(s). 2020 Open Access This article is licensed under a Creative Commons Attribution 4.0 International License, which permits use, sharing, adaptation, distribution and reproduction in any medium or format, as long as you give appropriate credit to the original author(s) and the source, provide a link to the Creative Commons licence, and indicate if changes were made. The images or other third party material in this article are included in the article's Creative Commons licence, unless indicated otherwise in a credit line to the material. If material is not included in the article's Creative Commons licence and your intended use is not permitted by statutory regulation or exceeds the permitted use, you will need to obtain permission directly from the copyright holder. To view a copy of this licence, visit http://creativecommons.org/licenses/by/4.0/ The Creative Commons Public Domain Dedication waiver (http://creativecommons.org/publicdomain/zero/1.0/) applies to the data made available in this article, unless otherwise stated in a credit line to the data. 
(Continued from previous page)

Results: HtrA1 was identified as a cisplatin resistance-related gene in NSCLC cells. The regulation of HtrA1 by HDAC and RXR significantly decreased the efficacy of cisplatin in NSCLC cells resistant to cisplatin. Immunohistochemistry results showed a negative relationship between HDAC1 and HtrA1, and a positive relationship between RXRa and HtrA1 in NSCLC patients' tissues. Notably, the expression of HDAC1 and HtrA1 can be considered as biomarkers for the efficacy of platinum-based drugs and prognosis in NSCLC patients. Mechanistically, the heterodimers of the nuclear receptor RXR, in combination with the enzyme, HDAC, regulate the transcription of HtrA1 in NSCLC cells. The rescue of HtrA1 expression by dual targeting of HDAC and RXR with the compound, DW22, significantly inhibited the proliferation, migration and invasion of NSCLC cells resistant to cisplatin, and induced NSCLC cell apoptosis.

Conclusion: Our results indicate that HtrA1, a cisplatin resistance-related gene, is synergistically regulated by HDAC and RXR in NSCLC. Targeting the HDAC/RXR/HtrA1 signaling axis can rescue HtrA1 expression and reverse cisplatin resistance in NSCLC.

Keywords: Cisplatin resistance, Lung cancer, HtrA1, HDAC, RXR

\section{Background}

Lung cancer is one of the most common malignant tumors worldwide, and is associated with a high rate of morbidity and mortality [1]. Non-small cell lung cancer (NSCLC) accounts for about $85 \%$ of global cases of lung cancer [2]. Currently, the drugs for clinical treatment of NSCLC can be divided into three categories based on their mechanism of action: cytotoxic, molecularly targeted and immunotherapeutic drugs [3]. Cytotoxic drugs generally produce their antitumor efficacy by interfering with the synthesis of nucleic acids and/or proteins [4]. The drugs commonly used in the clinic to treat NSCLC are cisplatin (CDDP), vinorelbine, and paclitaxel [5]. The most effective treatment for NSCLC is CDDP, which activates apoptosis-related pathways by inducing DNA damage [6]. However, as chemotherapeutic treatment progresses, the likelihood of drug resistance increases, thereby decreasing the therapeutic efficacy of CDDP [7]. It has been hypothesized that multiple mechanisms are involved in mediating resistance to $\operatorname{CDDP}[8,9]$. It has been reported that CDDP resistance in NSCLC can result from alterations in: 1) alteration of influx and efflux of drugs from the cancer cells, such as copper transporter CTR1 [10, 11], P-gp [12] and other transporters $[13,14]$; 2) enhancing the capacity for DNA repair, for instance, the upregulation of nucleotide excision repair related protein ERCC1 [15]; 3) downregulation of the expression of apoptosis proteins, including Bcl-2 and Bak $[7,16,17]$; 4) the change of important molecular signal pathways $[11,18,19]$, such as IGF and MAPK pathways. Some strategies against cisplatin resistance have achieved initial results. For instance, Sen et al found that CHK1 inhibitor LY2606368 improved the response of platinum-resistant models to CDDP [20]. In addition, Socinski MA et al reported targeting components in the tumor microenvironment, such as immune system treatment, is associated with better survival outcomes [21].
Currently, however, the exact mechanisms underlying cisplatin resistance in NSCLC remain to be determined, and the drugs that have been developed to treat drug resistant lung cancer, based on our existing knowledge of drug resistance mechanisms, have not had significant therapeutic efficacy $[8,11]$. Therefore, there is an urgent need to elucidate the mechanism of CDDP resistance in NSCLC and to develop novel and more efficacious drugs for lung cancer patients.

One approach in developing drugs to overcome CDDP resistance is to determine the expression of specific genes in these tumors. For example, high temperature requirement factor serine peptidase 1 (HtrA1) was the first identified member of the serine protease family [22, 23]. Recently, it has been reported that the downregulation of HtrA1 promotes the survival, as well as the invasion and migration of cancer cells [24, 25]. Functional studies indicate that HtrA1 regulates a number of signaling pathways and protein substrates that mediate anti-tumor efficacy [22, 26]. HtrA1 is primarily involved in the regulating the following biological functions: the transforming growth factor- $\beta$ (TGF- $\beta$ ) signaling pathway $[27,28]$, programmed cell death and apoptosis [29, 30], the EGFR/AKT pathway [31] and the inhibition of epidermal-interstitial transformation [25]. Studies have shown that the expression level of HtrA1 is negatively correlated to drug resistance and HtrA1 may be a target for drug development [32]. In NSCLC, the downregulation of HtrA1 mRNA and protein levels increases the number of tumor stem cell phenotypes in CDDPresistant cells [33]. However, the characteristics, molecular mechanisms, and regulation of HtrA1 in CDDP resistance remain to be elucidated.

In this study, we identified HtrA1 as a tumor suppressor gene that was involved in cancer cell proliferation and migration, and in CDDP resistance in NSCLC cells. Furthermore, the mechanisms that downregulate HtrA1 
in CDDP-resistant cells were elucidated, and a rescue strategy based on these regulatory mechanisms was devised to overcome CDDP resistance in NSCLC cells.

\section{Results}

The identification of HtrA1 as a cisplatin resistancerelated gene in NSCLC cells

To determine the mechanisms that produce CDDP resistance in NSCLC cells, we performed gene microarray analysis in paired NSCLC and NSCLC-CDDP resistant cell lines. Spell out GO (GO) analysis data indicated that serine peptidase activity was significantly increased in NCI-H460/CDDP cells compared to the parental cells (Fig. 1a). Further analysis indicated that several oncogenes, such as MMP2, MMP9 and BMP1, were significantly upregulated in resistant cells (Fig. 1b). However, several genes were downregulated in CDDP resistant cells, including HtrA1, a cancer-related gene. The above data were confirmed by real-time RT-PCR analysis (Fig. $1 \mathrm{c}$ and Fig. S1A-B).

To elucidate the mechanism that regulates HtrA1 expression, we analyzed the promoter region of the HtrA1 gene using Transfac and JASPAR software. The results indicated that there were several binding sites for the nuclear receptor, RXR (data not shown). In addition, Gene Set Enrichment Analysis (GSEA) analysis indicated that the activity of PPAR and RAR, which form heterodimers with RXR [34], was significantly reduced in NCIH460/CDDP cells and A549/CDDP cells (Fig. 1d and Fig. S1C). Furthermore, the acetyltransferase activity of NCI-H460/CDDP cells and A549/CDDP cells was also significantly decreased (Fig. 1d and Fig. S1C), suggesting that epigenetic regulation may be involved in this process. Next, we analyzed the activity of the epigenetic regulator, HDAC, and RXR, in three paired NSCLC cell lines. As shown in Fig. 1e and Fig. S1D, HDAC activity significantly increased, whereas RXR activity was significantly decreased in the resistant cell lines, consistent with the GSEA data. Furthermore, the expression of the HDACs proteins, including HDAC1 and HDAC6, was increased, whereas the expression of the RXR proteins was decreased, and the level of HtrA1 protein was significantly decreased in the CDDP resistant cell lines (Fig. if and Fig. S1E). To further clarify the role of HDACs in CDDP resistance, we treated NCI-H460/CDDP with HDAC6 specific inhibitors CG347B and pan-HDAC inhibitor SAHA. As shown in Fig. S1F, SAHA significantly increased the expression of HtrA1 in both mRNA and protein levels, while the HDAC6 inhibitor (CG347B) could not, suggesting that the total HDACs play a key role in HtrA1 regulation. Taken together, the above results indicate that HtrA1 is downregulated in CDDP resistant NSCLC cells, and the nuclear receptor RXR and the epigenetic regulatory enzyme HDAC may be involved in the regulation of HtrA1.

\section{The downregulation of HtrA1 by HDAC and RXR desensitizes NSCLC cells to CDDP}

Next, we investigated whether RXR and HDAC affect HtrA1 expression and mediates CDDP resistance in NSCLC cells. We determined the HtrA1 mRNA levels in CDDP resistant NSCLC cells by transient silencing of HDAC1, the main isoform of HDAC. In so doing, HtrA1 mRNA levels were significantly increased in the HDAC1 siRNA group compared to the scramble control group (Fig. 2a and Fig. S2A). We also determined HtrA1 mRNA levels in drug resistant cells that overexpressed RXR $\alpha$. The results indicated that HtrA1 mRNA levels were significantly increased in the RXR $\alpha$-overexpressing cells compared to the control group (Fig. 2b and Fig. S2B). To determine the possible synergistic regulation of HtrA1 by HDAC and RXR, we measured HtrA1 expression in A549/CDDP and NCI-H460/CDDP cells incubated with the HDAC inhibitors SAHA and panobinostat (LBH-589) or the RXR agonist, bexarotene (Bexa), either individually or in various combinations. The combination of the HDAC inhibitors and Bexa significantly up-regulated HtrA1 expression compared to the control and single-compound groups in CDDP resistant NSCLC cells (Fig. 2c, and Fig. S2C), as well as parental cells (Fig. S2D-E). The co-regulation model was also demonstrated by gene manipulation. Combination of HDAC knockdown and RXR overexpression synergistically increase HtrA1 expression in CDDP resistant NSCLC cells (Fig. S2F-G). These results confirmed the co-regulatory effect of HDAC and RXR on HtrA1 expression in CDDP resistant NSCLC cells. To exclude whether there is a inter-regulation between HDAC and RXR, we detected the expression of them after treated with Bexa or SAHA. As shown in Fig. S2H, the expression levels of three RXR isoforms and HDAC1 did not change, suggesting their independent regulatory role. Next, we determined the efficacy of CDDP in paired NSCLC cells to CDDP after HtrA1 manipulation. Indeed, the efficacy of CDDP was significantly decreased in the parental NSCLC cells after the knock-down of HtrA1, whereas the efficacy of CDDP was significantly increased in CDDP-resistant NSCLC cells overexpressing HtrA1 (Fig. 2d-e).

To clarify the role of HtrA1, we performed migration assays in parental cells after transiently silencing HtrA1. Following the silencing of HtrA1, the migration of parental cells was significantly increased (Fig. 2f and Fig. S2I). Furthermore, the role of HtrA1 in anti-tumorigenesis and CDDP resistance was assessed by an in vivo study. Compared with the vehicle control group, the knockdown of HtrA1 in NCI-H460 cells resulted in a significant increase 

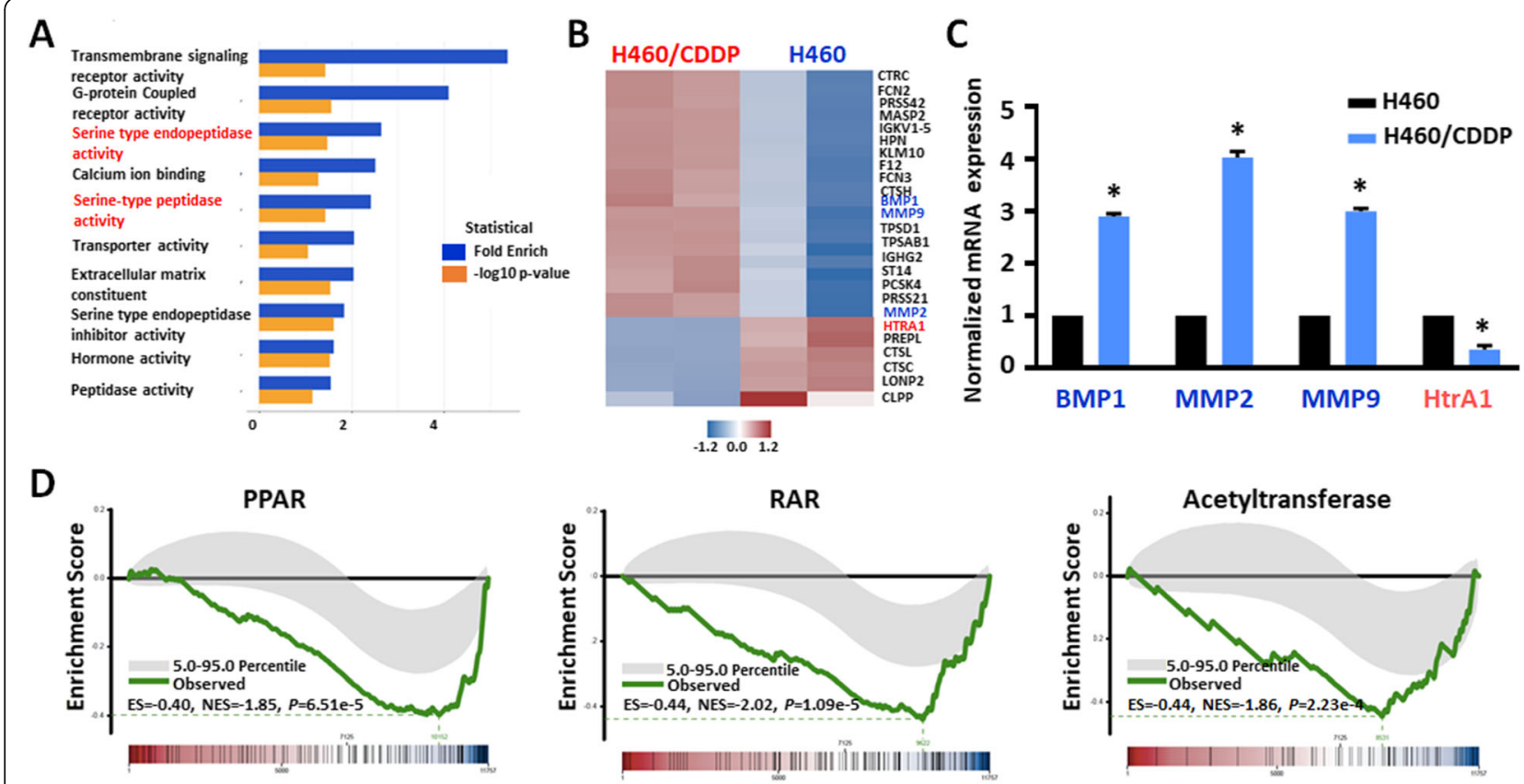

E
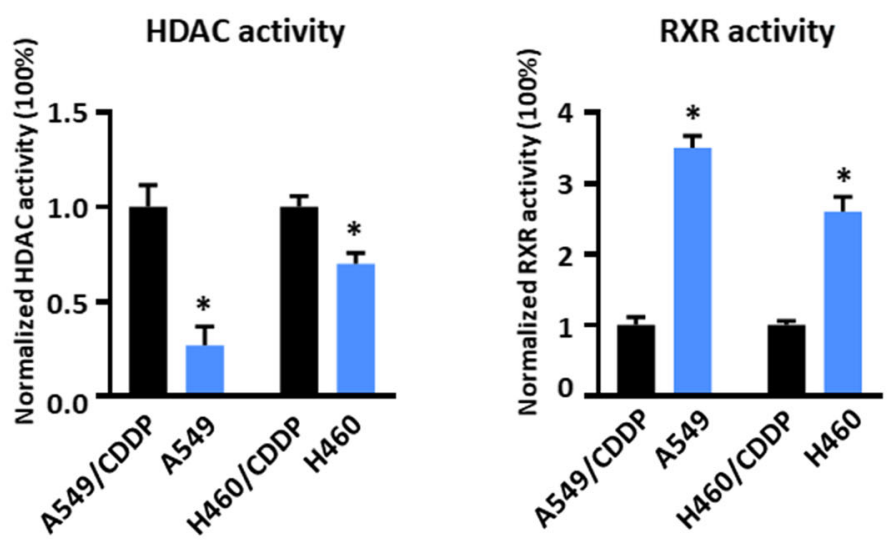

F

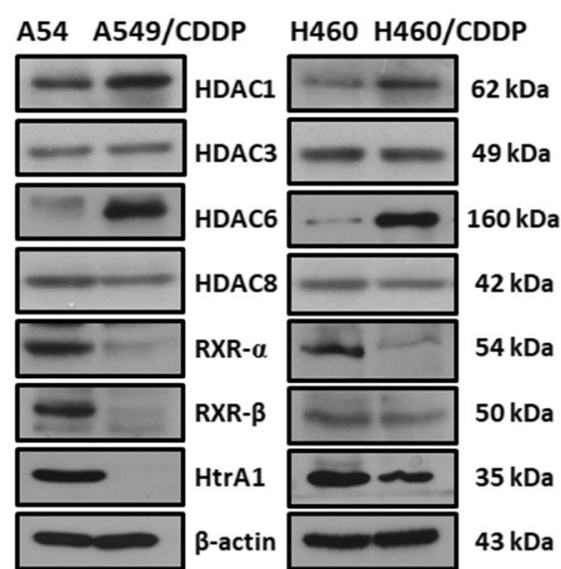

Fig. 1 Identification of HtrA1 as a cisplatin resistance-related gene in NSCLC. a. The differential expression of genes in parental and NCl-H460/ CDDP cells was compared using gene microarray analysis. The figure shows GO analysis (molecular function, MF) of the differentially expressed genes. Functions highlighted in red represent serine-type endopeptidase activity and serine-type peptidase activity. $\mathbf{b}$ and $\mathbf{c}$. The differential expression of genes in NCl-H460 and NCl-H460/CDDP cells by $\mathbf{b}$, gene microarray analysis and $\mathbf{c}, \mathrm{RT}-\mathrm{PCR}$. $\mathbf{d}$. GSEA analysis of PPAR, RAR and acetyltransferase activity in NCI-H460/CDDP cells. e. The activity of HDAC and RXR in CDDP resistant and parental cells. f. The protein expression levels of the main isoforms of HDAC and RXR in CDDP resistant cells and parental cells. ${ }^{*} P<0.05$, as compared to the parental cell group with the CDDP-resistant cell group

in tumor growth (Fig. 2g). In addition, in vivo data indicated that NCI-H460 xenograft tumors where HtrA1 was knocked down were more resistant to CDDP (inhibition rate $21 \%$ ) than control NCI-H460 xenograft tumors without the knockdown of HtrA1 (inhibition rate 56\%) (Fig. 2g).

To further determine if HtrA1's efficacy in cisplatin resistance is dependent on its enzyme activity, we created a catalytically dead mutant of HtrA1 (S328A), and overexpressed the HtrA1 wild-type and dead-mutant in A549/CDDP cells. The efficacy of CDDP was significantly increased in the group expressing wild-type
HtrA1, but not in the group expressing the dead-mutant (Fig. 2h). Similarly, in the A549/CDDP cell line, wildtype HtrA1 overexpression significantly reduced cell migration, whereas cell migration was not decreased in the dead-mutant (Fig. 2i).

The relationship between HDAC, RXR and HtrA1 in NSCLC cases and their clinical significance in NSCLC

To confirm the relationship between HDAC, RXR, and HtrA1, we determined their expression levels in tissue specimens from 101 platinum-treated NSCLC patients 

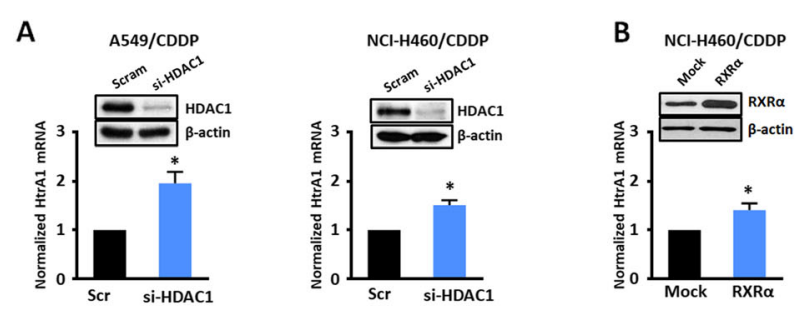

C

D

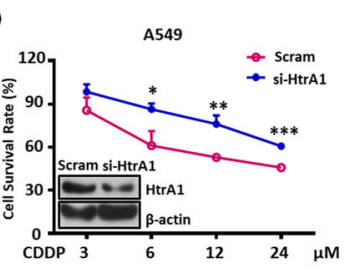

E
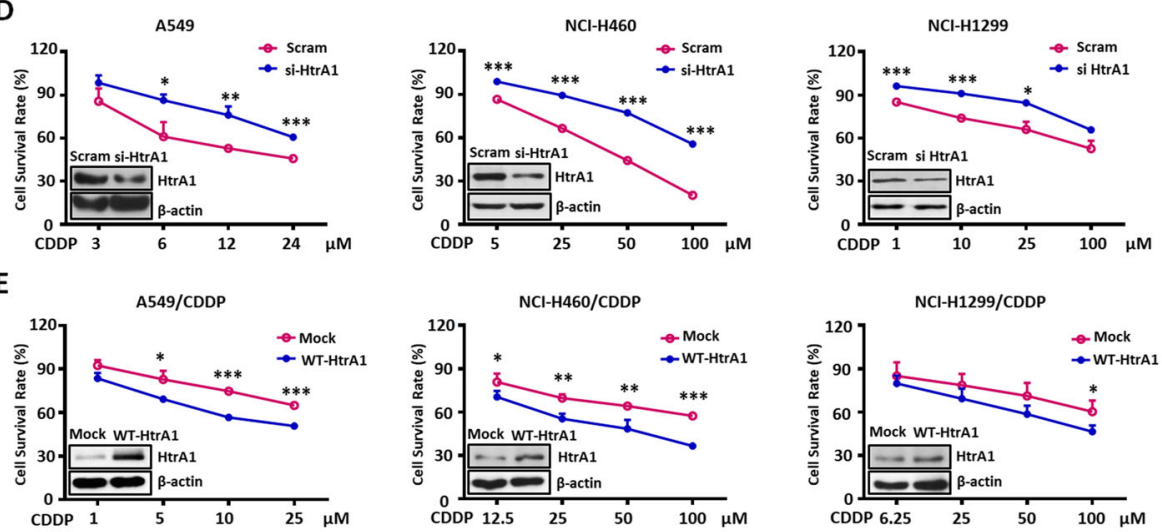

$\mathbf{F}$

G
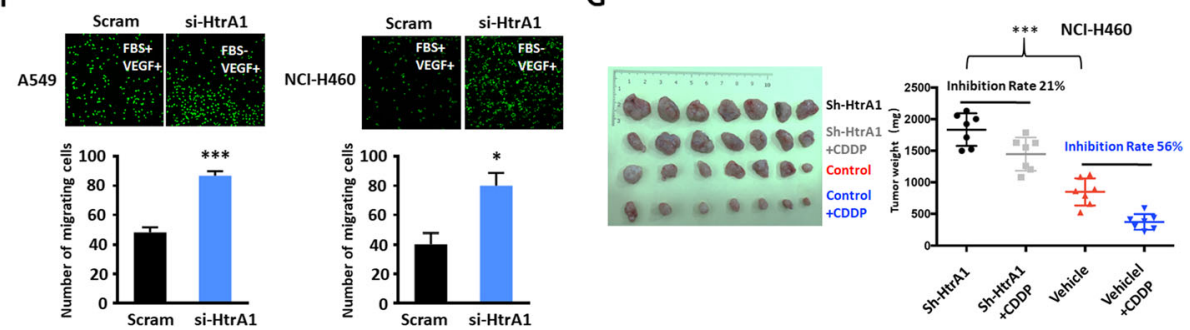

H
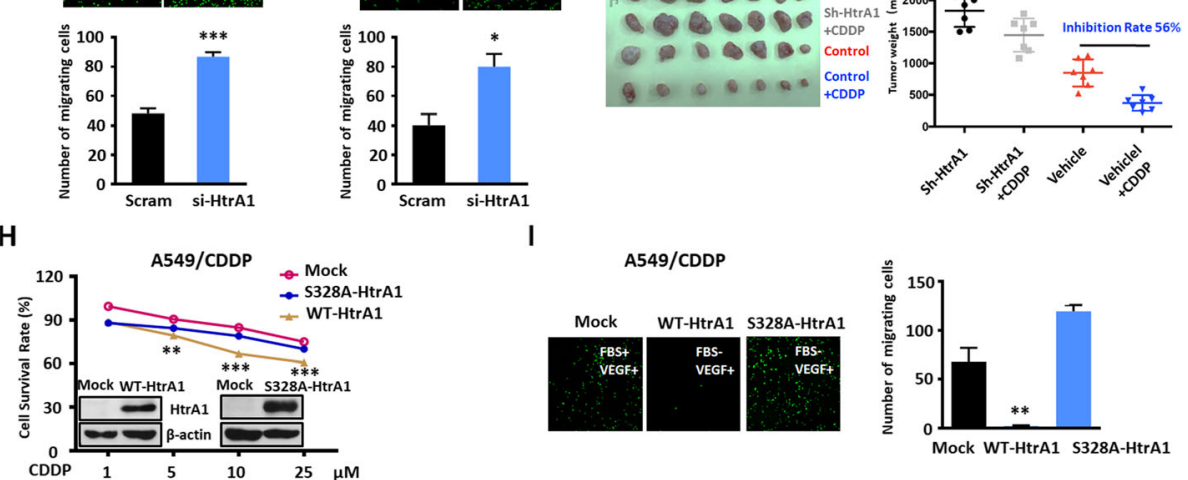

Fig. 2 The downregulation of HtrA1 by HDAC and RXR increases the efficacy of cisplatin in NSCLC cells. a. RT-PCR analysis of HtrA1 in CDDP resistant NSCLC cells transfected with HDAC1 siRNA or control siRNA (Scramble). b. RT-PCR analysis of HtrA1 mRNA levels in the NCI-H460/CDDP cell line transfected with a RXRa overexpression or control plasmid. c. RT-PCR analysis of HtrA1 mRNA levels in NCI-H460/CDDP cells incubated with bexarotene (Bexa), SAHA or a combination of bexarotene and SAHA for $24 \mathrm{~h}$. The final concentrations were: SAHA $(5 \mu \mathrm{M})$, bexa $(20 \mu \mathrm{M})$, SAHA+bexa $(5 \mu \mathrm{M} / 20 \mu \mathrm{M})$. d. MTT assay results indicating the efficacy of CDDP in parental NSCLC cells transfected with HtrA1 siRNA or control siRNA for $48 \mathrm{~h}$. e. MTT assay results indicating the efficacy of CDDP in CDDP resistant NSCLC cells transfected with HtrA1 overexpression or control plasmid for $48 \mathrm{~h}$. f. Cell migration assay in parental NSCLC cells transfected with HtrA1 siRNA or control siRNA. $\mathbf{g}$. The inhibitory efficacy of CDDP treatment on tumor weight in mice with $\mathrm{NCl}-\mathrm{H} 460 \mathrm{shHtrA} 1$ and vehicle xenografts. $\mathbf{h}$. MTT assay results indicating the CDDP sensitivity of A549/CDDP cells transfected with HtrA1 overexpression (S328A or WT) or control plasmid. i. Cell migration in A549/CDDP cells transfected with HtrA1 overexpression (S328A or WT) or control plasmid. ${ }^{*} P<0.05,{ }^{* *} P<0.01,{ }^{* * *} P<0.001$, as compared to the scram or mock group

using immunohistochemistry. The results indicated that $74 \%$ of patients with low levels of HtrA1 expression $(n=$ $37)$ were in the high HDAC1 expression group $(n=50)$, whereas $59 \%$ of patients with higher HtrA1 expression $(n=30)$ were in the low HDAC1 expression group $(n=$ 51). These results indicated that HDAC1 expression was negatively correlated with HtrA1 expression in platinum-treated NSCLC cases $(P<0.001$, Fig. 3a and b). In contrast to $\mathrm{HDAC1}, \mathrm{RXR} \alpha$ expression was positively correlated with the expression of HtrA1 in NSCLC cases $(P<0.01$, Fig. $3 \mathrm{a}$ and $\mathrm{b})$. Furthermore, the downregulation of HtrA1 was non-significantly correlated with a poor response to treatment $(P=0.056$, Fig. $3 c)$ and significantly correlated with a poor overall survival $(P<$ 


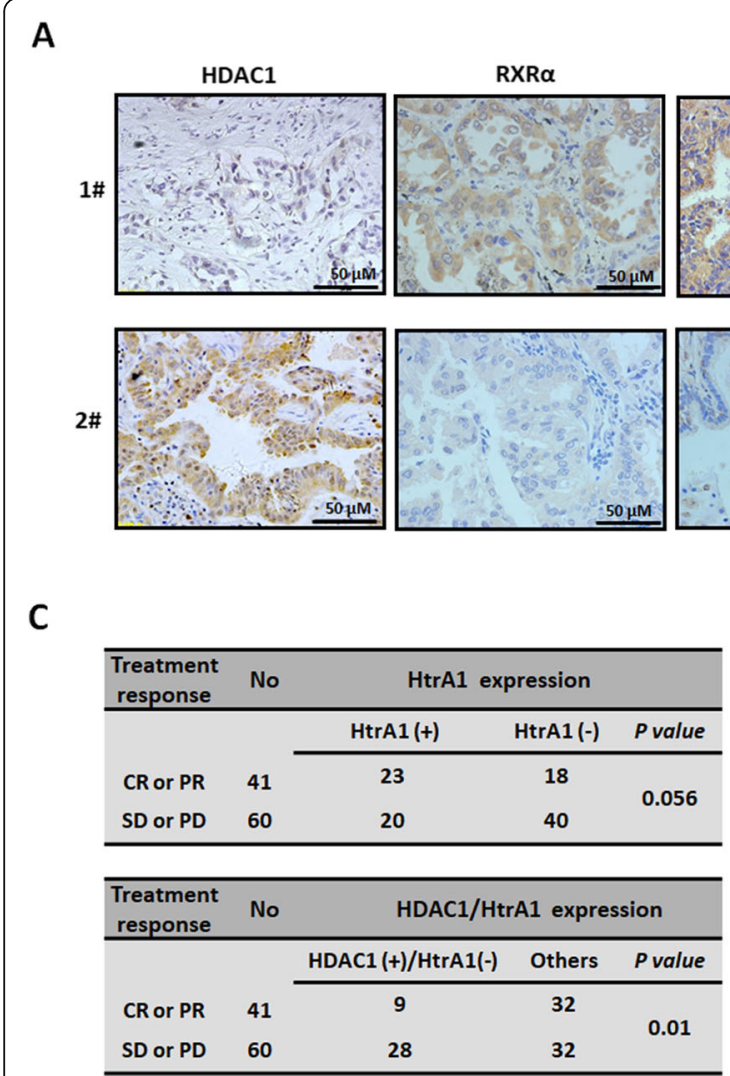

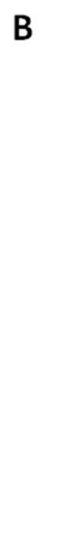

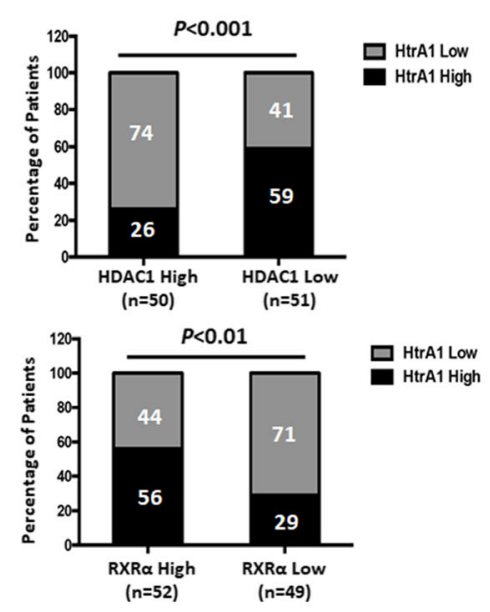

D
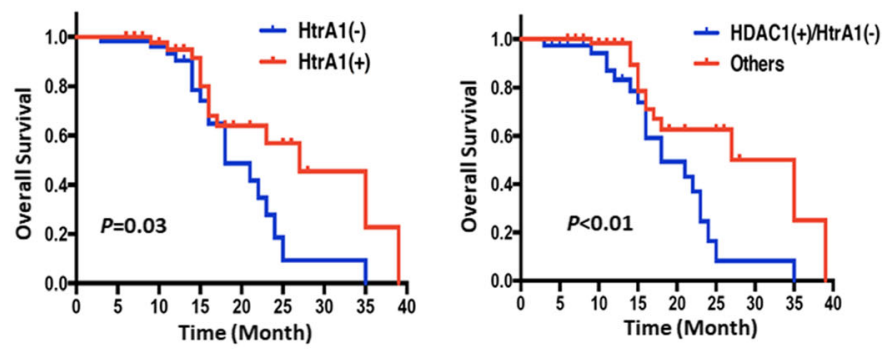

Fig. 3 The relationship between HDAC, RXR and HtrA1 in NSCLC cases and their clinical significance in NSCLC. a. Representative sections of NSCL C tumor tissues from two patients treated with platinum. The expression of HDAC1, RXRa and HtrA1 was detected using immunohistochemistry. Patient 1\# was HDAC1 low/RXRa high/HtrA1 high. Patient 2\# was HDAC1 high/RXRa low/HtrA1 low. b. Statistical analysis of the expression patterns of HDAC1, RXRa and HtrA1 in tissue specimens from 101 NSCLC patients treated with platinum. $\mathbf{c}$ and $\mathbf{d}$. Correlation of the expression of HtrA1 protein with $\mathbf{c}$ the treatment response and $\mathbf{d}$ the overall survival. CR, complete response; PR, partial response; SD, stable disease;

PD, progressive disease

0.05, Fig. 3d). Importantly, the opposite expression pattern (higher HDAC1 and lower HtrA1 expression levels) was significantly correlated with a poor treatment response and poor overall survival compared to the other NSCLC groups (Fig. 3c and d). Notably, the PROGgeneV2 tool (using the GSE30219 database, Fig. S3) also showed that the high HDAC1/low HtrA1 expression pattern was significantly correlated with a poor prognosis. Overall, the immunohistochemistry data further confirmed the interaction between $\mathrm{HDAC} 1, \mathrm{RXR} \alpha$, and HtrA1, and suggested that HtrA1, especially in combination with HDAC1, may be used as a predictive biomarker for platinum treatment response and prognosis in patients with NSCLC.

\section{The transcriptional activation of HtrA1 is dependent on heterodimeric RXRa complexes and HDAC activity}

To further investigate the molecular mechanism of HtrA1 regulation, we used luciferase reporter assays to analyze transcription factor binding sites in the promoter of the HtrA1 gene. First, we constructed a series of reporter plasmids containing the full-length HtrA1 gene promoter (pGL3-HtrA1-P1) or with three deletions (pGL3-HtrA1-P2, P3, and P4; Fig.4a). We next determined the reporter gene activity in CDDP resistant and parental NSCLC cells using a dual luciferase reporter assay. Similar patterns of transcriptional activity were seen in both resistant cells and parental cells (Fig. 4b and Fig. S4A). The P3 region, which includes an RXR $\alpha$ binding site, had the highest activity in all four cell lines tested, suggesting that RXR $\alpha$ may act as a transcriptional activator in the HtrA1 promoter regulation. In addition, our data indicated that CDDP resistant cells had a higher reporter activity than the parental cells, providing further evidence that HtrA1 plays a role in CDDP drug resistance (Fig. S4B). To identify the functional binding site of RXR $\alpha$, we mutated four RXR $\alpha$ binding sites alone or in different combinations in PGL3-HtrA1-P1. As shown in Fig. 4c and Fig. S4C, the luciferase activity of HtrA1 was significantly decreased when mutated M4' site while no significant changes when mutated other sites or in combination, indicating RXR $\alpha$ binding site on 
A

C

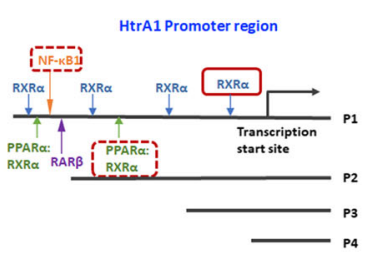

NCI-H46O/CDDP

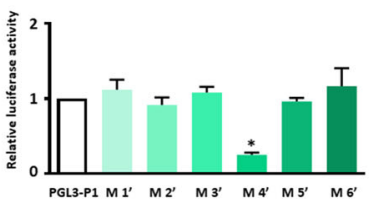

B

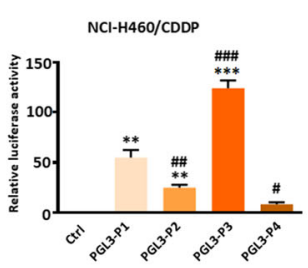

D

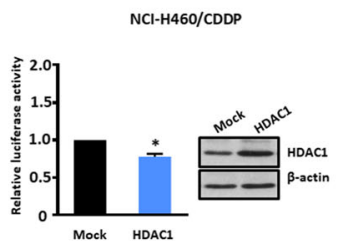

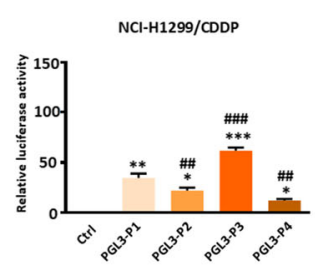

NCl-H1299/CDDP

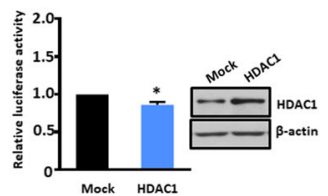

E

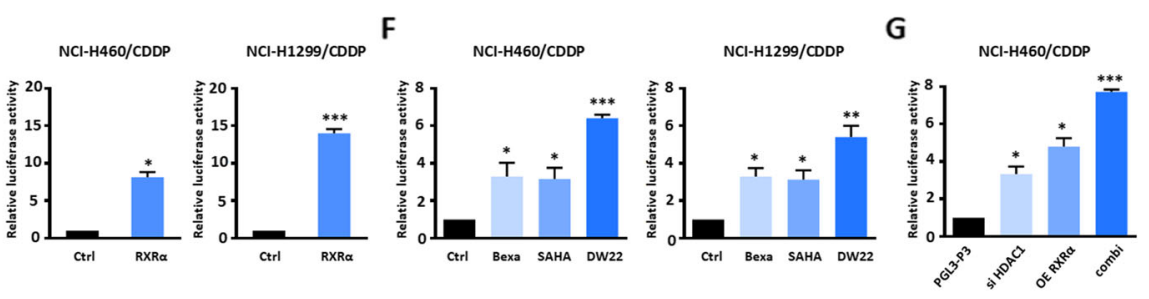

H
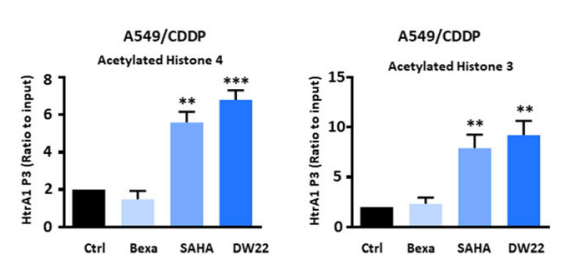

I
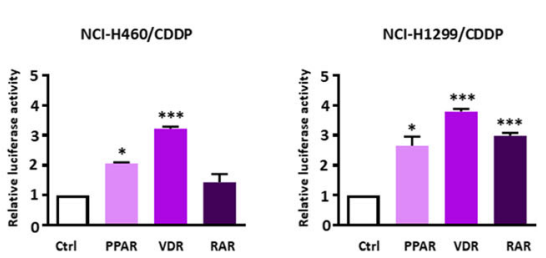

J
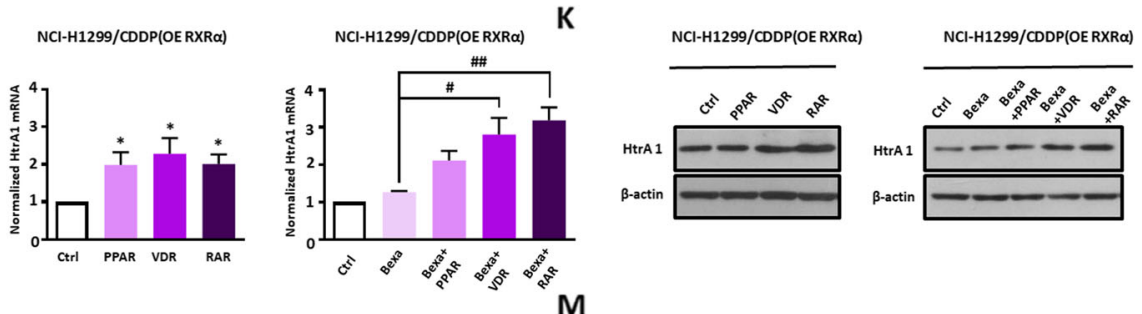

L
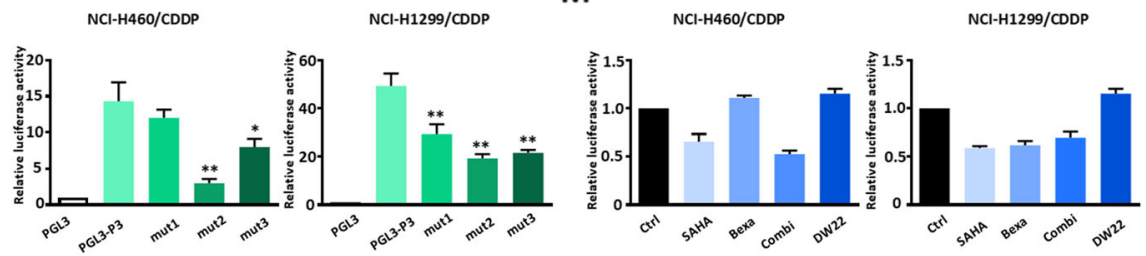

Fig. 4 (See legend on next page.) 


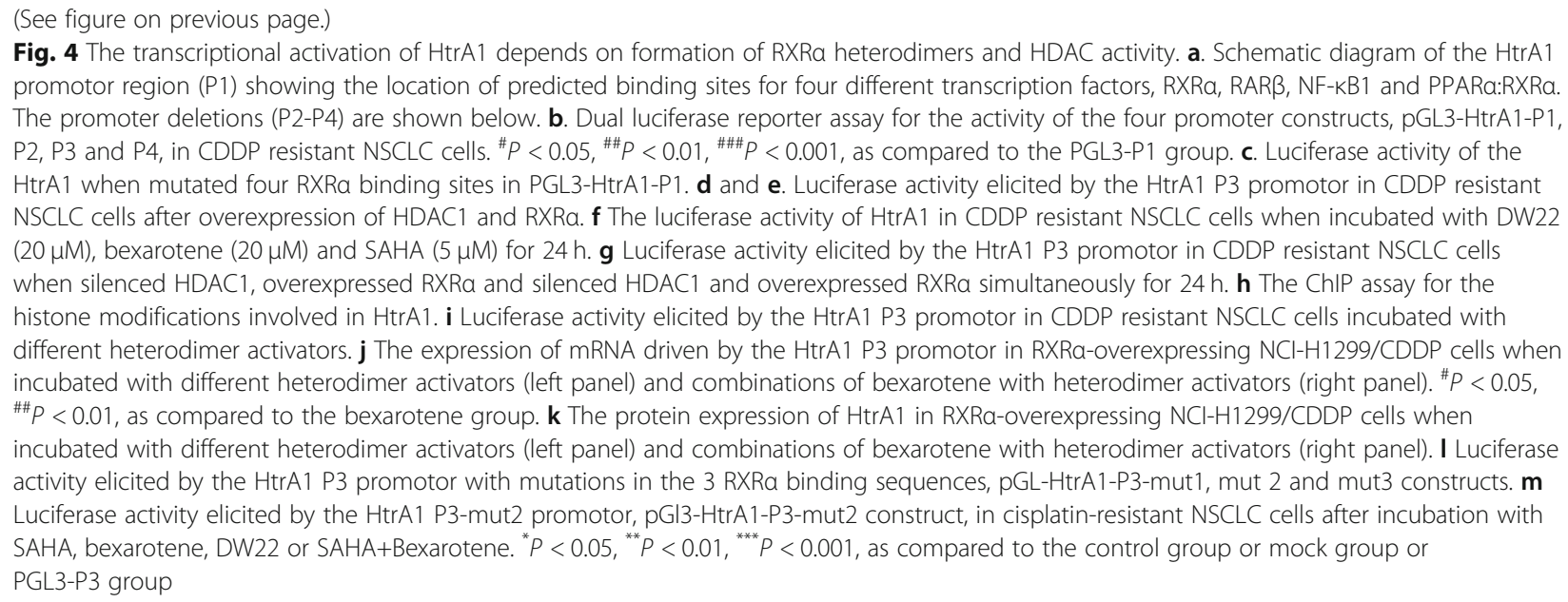

P3 plays an important role in transcriptional activation of HtrA1. Next, to determine the epigenetic regulation of HtrA1, we overexpressed HDAC1 in NSCLC cells transfected with the pGL3-HtrA1-P3 reporter construct. The overexpression of HDAC1 in drug resistant cells weakly decreased luciferase activity, suggesting that HDAC1 regulate the transcriptional activity of the HtrA1 promoter to a certain extent (Fig. 4d). Similar results were obtained in parental cells (Fig. S4D). The overexpression of RXR $\alpha$ in both resistant and parental cells significantly increased the activity of the HtrA1 reporter construct, suggesting that RXR $\alpha$ activates HtrA1 transcription (Fig. 4e and Fig. S4E). To further investigate the transcriptional regulation of HtrA1 by RXR and HDAC, we measured pGL3-HtrA1-P3 reporter activity in resistant and parental cells incubated with bexarotene, SAHA, and DW22 (Fig. 4f and Fig. S4G). DW22 is a novel dual-target compound, previously discovered by our research group, that inhibits HDAC while activating RXR [35] (Fig. S4F). The results showed that the activity of the reporter was increased after incubation with SAHA or bexarotene in CDDP resistant cells (Fig. 4f). As expected, the activity after incubation with DW22 was significantly increased in higher degree (Fig. $4 \mathrm{f}$ and Fig. S4G). Besides, the fact that combination of HDAC knockdown and RXR overexpression synergistically increased the transcriptional activity of the HtrA1 promoter in CDDP resistant NSCLC cells confirmed the coregulatory effect of HDAC and RXR on HtrA1 (Fig. 4g). The ChIP assay was performed to assess epigenetic regulation, including Acetylated Histone 3 and Histone 4, and the ability of the transcription factor, RXR $\alpha$, to bind to specific sites on the HtrA1 promoter fragment P3. The results indicated that similar with SAHA, DW22 also increased directly binding of the acetylated $\mathrm{H} 4$ and acetylated $\mathrm{H} 3$ to $\mathrm{HtrA} 1$ promoter in drug resistant cells (Fig. 4h). Also, the ability of RXRo's binding to HtrA1 promoter was enhanced by DW22 in drug resistant cells (Fig. S4H). The above data confirmed the synergistic regulation of HtrA1 by HDAC and RXR.

RXR forms homodimers with itself or heterodimers with the retinoic acid receptor (RAR), vitamin D receptor (VDR) and peroxisome proliferator-activated receptor (PPAR), to regulate signal transduction pathways involved in processes such as cell proliferation, differentiation, metabolism and apoptosis [9]. Therefore, we incubated resistant and parental cells with pioglitazone, a PPAR agonist, calcitriol, a VDR agonist and tamibarotene, a RAR agonist, to verify whether the regulatory function of RXR is dependent on a heterodimeric transcriptional complex. All three of the aforementioned agonists significantly increased HtrA1 reporter gene activity in NCI-H1299/CDDP cells, with calcitriol producing the greatest increase, at the same time, VDR agonist calcitriol also significantly increased HtrA1 reporter gene activity in other cells. (Fig. 4i and Fig. S4I). Thus, RXR may depend on the formation of heterodimeric transcriptional complexes to regulate the HtrA1 gene. Interestingly, there was no significant change in HtrA1 mRNA and protein expression in both parental cells and resistant cells following treatment with the heterologous agonists, pioglitazone, calcitriol and tamibarotene (Fig. S4J and Fig. S4K). We also combined RXR homologous agonists with heterologous agonists and determined their effect on the regulation of HtrA1 mRNA expression. However, the activity of the reporter construct was increased slightly, indicating that only the combination of agonists did not dramatically increase the level of HtrA1 (Fig. S4L). Consequently, we hypothesized that endogenous RXR $\alpha$ does not affect the transcription process of HtrA1 gene in the presence of an additional agonist.

Next, we determined the levels of HtrA1 mRNA and protein in RXR $\alpha$-overexpressing NCI-H1299/CDDP cells incubated with heterodimeric agonists and bexarotene 
(Fig. 4J and Fig. 4K). We found that bexarotene/RAR was potent and bexarotene/VDR was medium, while bexarotene/PPAR showed a weak effect on the expression of HtrA1. These data suggest that RXR $\alpha$ plays an important role in the transcriptional activation of HtrA1, and this is dependent on the formation of a heterodimer. In order to confirm the role of RXR $\alpha$ in the regulation of HtrA1, we mutated the RXR $\alpha$ binding sites within the HtrA1 promoter fragment P3 to create the reporter constructs, pGL3-HtrA1-P3-mut1, mut2 and mut3 (Fig. S4M). We then determined the transcriptional activity of these reporters in cells incubated with a RXR $\alpha$ agonist, Bexarotene and a HDAC inhibitor, SAHA. The luciferase activity of the pGL3-HtrA1-P3-mut2 was decreased in all cells, suggesting that HtrA1 transcription activity is dependent on RXR $\alpha$ (Fig. $4 \mathrm{l}$ and Fig. S4N). Importantly, there were no significant effects on HtrA1 transcriptional activity in resistant cells and parental cells transfected with pGL3-HtrA1-P3-mut2 plasmid after incubation with SAHA, bexarotene and DW22 (Fig. 4m and Fig. S4O). The regulation of HtrA1 by RXR and HDAC was further confirmed by ChIP assay to detect RXR $\alpha$ binding. As shown inFig. S4P, we found overexpression of RXR $\alpha$ led to increase RXR $\alpha$ binding to HtrA1 promoter, and treatment with Bexa, SAHA and DW22 could further promote RXR $\alpha$ binding. On the contrary, mutation in mut 2 point could result in the binding reduction. Similary, co-expression HDAC1 also contribute to decrease of RXR $\alpha$ binding. The Overall, the results suggest that RXR is an important transcriptional activator of the HtrA1 gene, whereas HDAC contributes to transcription repression of HtrA1 gene.

\section{The dual-target compound, DW22, mediates its anti- cancer efficacy in cisplatin-resistant cells by regulating HtrA1 expression}

Our experiments provide information about the molecular mechanisms by which HDAC and RXR $\alpha$ regulate the expression of HtrA1, and how the HDAC/RXR/HtrA1 signaling axis affects the efficacy of CDDP in NSCLC cells. Therefore, we hypothesized that suppressing this signaling axis may represent a potential approach for the reversal of CDDP resistance. As shown in Fig. 5a and b, the combination of DW22 and CDDP had a synergistic effect on the inhibition of cell growth. Compared to the parental cells, the synergistic effect was greater in NCIH460/CDDP and NCI-H1299/CDDP cells (Fig. S5A-B). Typically, resistant cells have an increased capacity for invasion and migration compared to parental cells, and this was confirmed by our results (Fig. S5C). Single treatment in CDDP resistant cells with SAHA, LBH-589 or Bexarotene moderately inhibited the invasion and migration ability, and the inhibitory effect was more significant when SAHA, LBH and Bexarotene were used simultaneously or when DW22 was used (Fig. S5D-G). These results indicate that dual targeting of HDAC and RXR increases the inhibition of cell migration and invasion. Notably, the combination of DW22 and CDDP produced a significant inhibition of migration (Fig. 5c) and invasion (Fig. 5d) in CDDP-resistant NSCLC cells compared to incubation with only one compound.

Next, we conducted additional experiments to determine the role of the HDAC/RXR/HtrA1 signaling axis in mediating the efficacy of DW22 to reverse resistance to CDDP. As shown in Fig. S5H-I, the mRNA and protein expression levels of HtrA1 were enhanced by DW22 treatment in NCI-H460/CDDP resistant cells. Next, we determined the efficacy of DW22 when HDAC, RXR and HtrA1 were silenced, or when HtrA1 was overexpressed. NCI-H460/CDDP cells became more sensitive to DW22 to reverse resistance to CDDP after transfection with HDAC1 siRNA, whereas the opposite effect occurred in NCI-H460 cells after transfection with RXR $\alpha$ siRNA (Fig. 5e-f). To determined the effect on HtrA1, we knocked down HtrA1 in A549 cells, and then incubated the cells with DW22. The result indicated that DW22 was less efficacious in the HtrA1 knockdown group compared to the scramble control (Fig. 5g). Next, we overexpressed HtrA1 in A549/CDDP cells. As predicted, the overexpression of wild-type HtrA1 in A549/ CDDP cells increased the sensitivity to DW22 (Fig. 5h). Interestingly, overexpressing the dead-mutant (S328A) HtrA1 in A549/CDDP had no significant effect on the cell sensitivity to DW22 compared to mock cells. Thus, HtrA1-induced sensitivity to DW22 requires the enzymatic activity of HtrA1. These results show that the dual targeting of HDAC and RXR by DW22 can reverse CDDP resistance in NSCLC, and this reversal was dependent on the HDAC/RXR/HtrA1 signaling axis.

\section{DW22 decreases CDDP resistance in NSCLC by rescuing HtrA1 in vivo}

We conducted experiments to validate the above in vitro results using an in vivo model. We used NCI-H460/ CDDP and A549/CDDP xenograft models to determine the inhibitory efficacy resulting from targeting $\mathrm{HDAC} /$ RXR/HtrA1 in vivo. NCI-H460/CDDP or A549/CDDP cells were injected into the flanks of male nude mice. In the NCI-H460/CDDP mice treated with CDDP or DW22 alone, the tumors were significantly larger and greater in weight compared to tumors in mice treated with DW22 and CDDP (Fig. 6a-b). Interestingly, treatment with SAHA, bexarotene and CDDP also significantly reduced NCI-H460/CDDP tumor growth, further confirming that the dual targeting of HDAC and RXR reverses CDDP resistance. Furthermore, the combination of DW22 and CDDP also significantly reduced the tumor burden in the A549/CDDP xenograft model (Fig. 


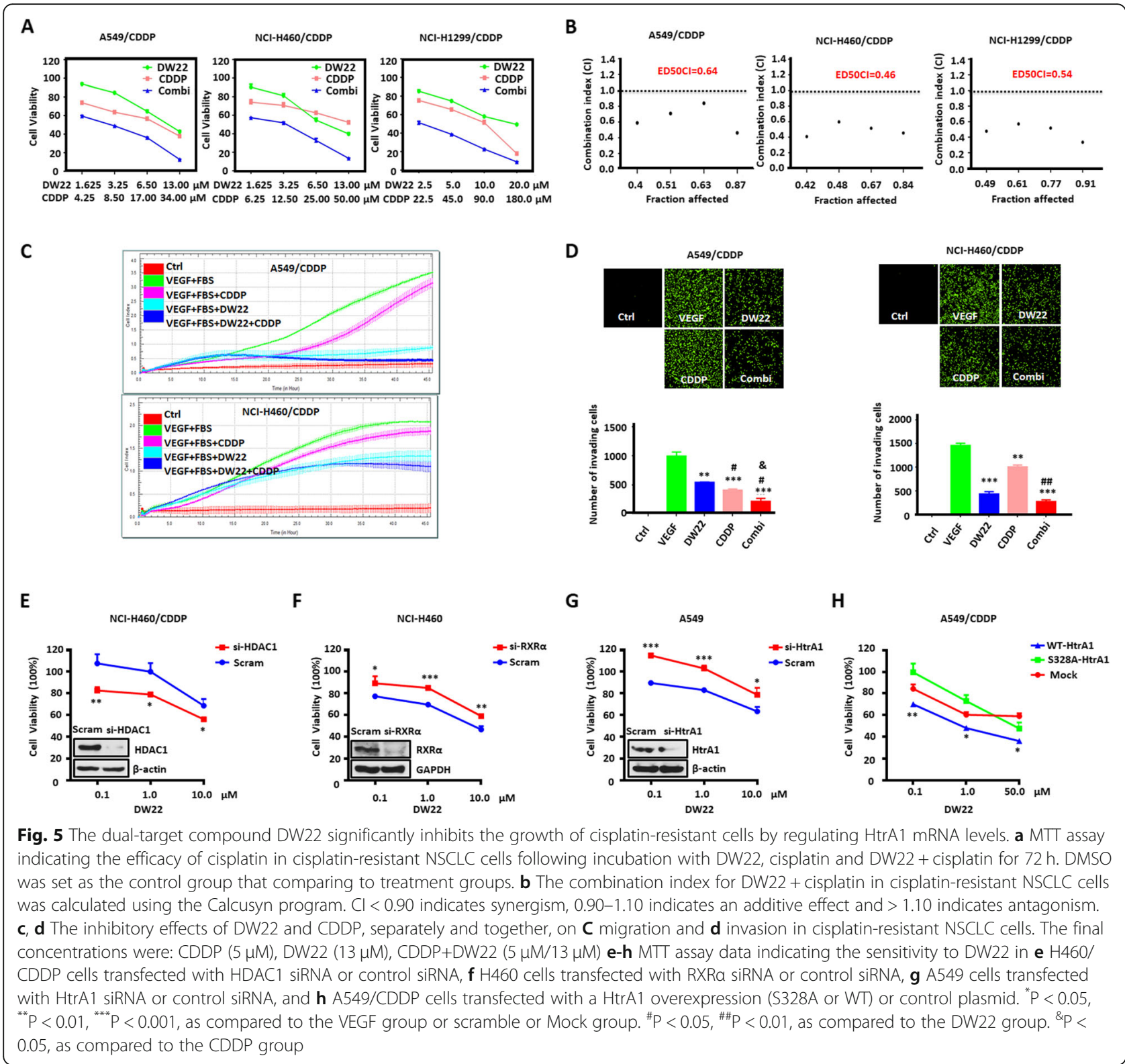

S6A). The representative images of tumor were exhibited in Fig. 6a and Fig. S6A. Moreover, there was no significant change between CDDP group and combined treatment group in the body weight and viscera index in the both xenograft mice model (Fig. 6c, Fig. S6B, C). TUNEL staining (Fig. 6d) also confirmed that SAHA/bexarotene/ CDDP and DW22/CDDP significantly induced cell apoptosis (TUNEL-positive cells). In addition, the proapoptosis action in the combination of DW22 and CDDP treatment was further confirmed by the increase of Bax, cleaved PARP, cleaved Caspase 3 and decrease of Bcl-2 (Fig. S6D) in A549/CDDP tumor tissues. Western blot data also indicated that the increased the expression of HtrA1 by up-regulating the level of acetylated Histone4 in SAHA/bexarotene/CDDP and DW22/CDDP treated NCI-H460/CDDP tumor tissues (Fig. 6e, Fig. $\mathrm{S6E})$. It is possible that these results are due to the dissociation of DNA that is facilitated by the acetylation of Histone4, producing an opening of the chromatin, thereby increasing the transcription of tumor suppressor genes. The above data indicate that DW22 can reverse CDDP resistance in two xenograft models by inducing cell apoptosis and upregulating HtrA1 expression.

\section{Discussion}

NSCLC, the most common type of lung cancer, produces significant morbidity and mortality [2]. CDDP is one of the most effective treatments for NSCLC, but CDDP-treated patients are usually prone to developing drug resistance $[8,9]$. The mechanisms of CDDP 


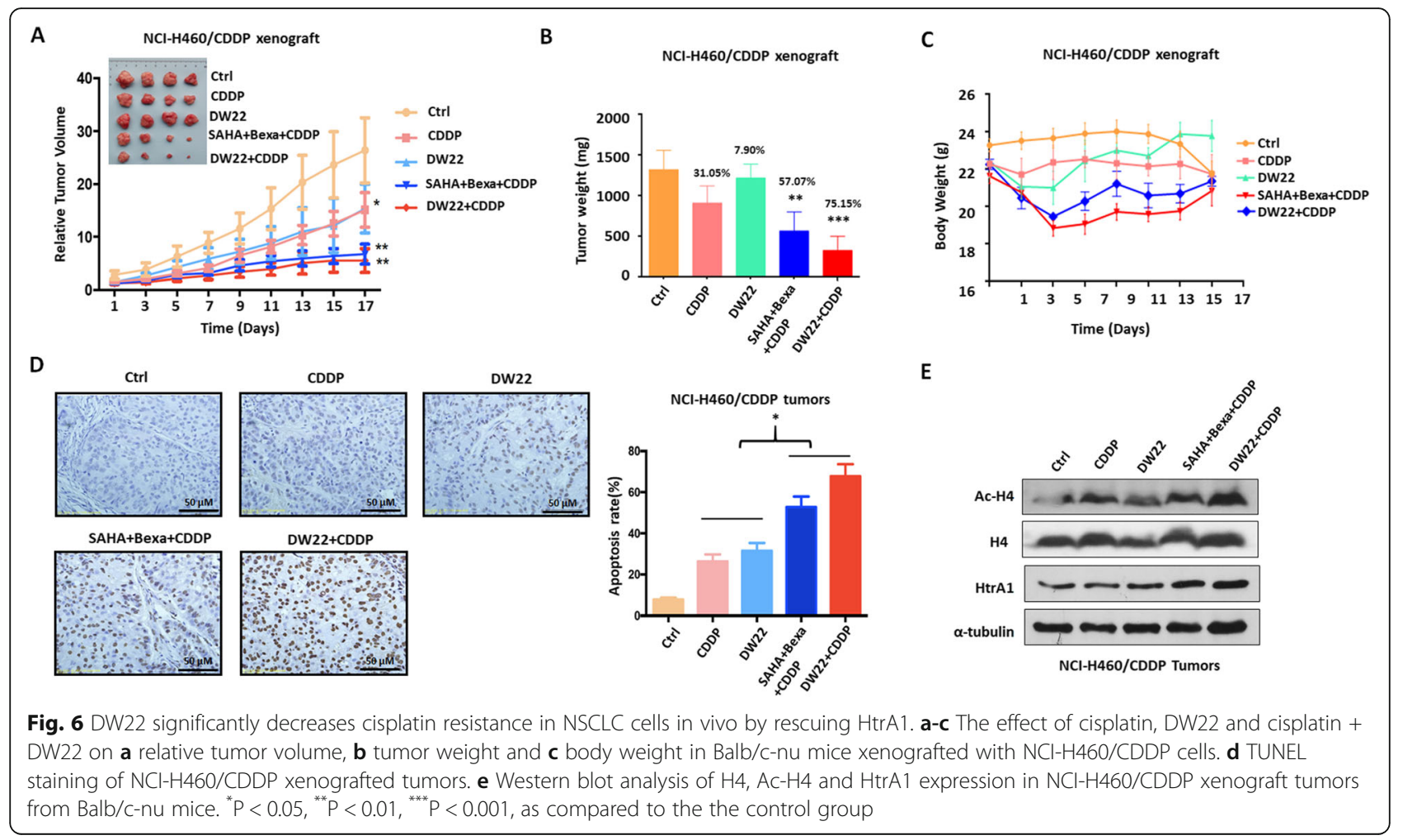

resistance have been explored for decades, and recent research indicates that a decrease in HtrA1 expresison is correlated with drug resistance [32, 36]. In this study, our gene microarrays and bioinformatics data indicated that the expression of HtrA1 and RXR were downregulated and HDAC expressed was upregulated in CDDPresistant NSCLC cells. HtrA1 mRNA levels were significantly increased when HDAC1 was transiently silenced or RXR $\alpha$ was overexpressed in CDDP-resistant NSCLC cells. Based on previous results and our present data, we hypothesized that the downregulation of HtrA1 was significantly correlated with HDAC overexpression and RXR downregulation in CDDP-resistant NSCLC cells. Our hypothesis was substantiated by data indicating the incubation of CDDP-resistant NSCLC cells with the HDAC inhibitor, vorinostat and the RXR agonist, bexarotene, significantly increased the levels of HtrA1. Given our results indicating that HtrA1 expression is involved in mediating CDDP resistance, we transiently silenced HtrA1 in the parental cells and overexpressed HtrA1 in CDDP-resistant cells. The CDDP sensitivity and invasion ability were increased in the parental cells,while were decreased in CDDP-resistant cells. Finally, our in vivo xenograft data indicated knockdown of HtrA1 in NCI$\mathrm{H} 460$ cells resulted in a significant increase in tumor growth (see Fig. 2).

Recent studies indicate that epigenetic mechanisms associated with abnormal regulation of gene expression occur frequently in NSCLC tumors [37]. Epigenetic changes are involved in the development and progression of tumors and may contribute to the development of resistance by interfering with tumor growth regulation pathways and proapoptotic programs [38]. We previously reported that histone deacetylase (HDAC) was activated in paclitaxel-resistant NSCLC cells, increasing proliferation and tumorigenesis of paclitaxel-resistant NSCLC cells in vitro and in vivo [39]. In addition, we have shown that CDDP played a role in the increased activity of HDAC, and the combination of vorinostat and cisplatin produced a 1) synergistic anti-cancer efficacy in NSCLC cell lines in a TRIB1-dependent manner and 2) significant decrease in tumor size and weight in mouse xenograft models [40]. These findings indicated that HDAC expression is significantly positively correlated with drug resistance in tumor cells, and its expression level and activity are significantly increased in drugresistant cells and negatively correlated with the prognosis of NSCLC patients [41]. Recently, it has been reported that HDAC inhibitors such as vorinostat and panobinostat, which are approved by the FDA, can reverse the malignant phenotype of CDDP-resistant NSCL $\mathrm{C}$ and when used with CDDP, they inhibit the growth of NSCLC [42, 43], which further demonstrate the potential value, as a anti-drug resistance strategy, based on HDAC therapy. Furthermore, it also should be noted that there are several HDAC subtypes involved into 
development and progression in cancer. In the present study, we found HDAC1 and HDAC6 were upregulated in CDDP-resistant NSCLC cells, but not HDAC3 and HDAC8, suggesting that the expression of specific HDACs are positively correlated with CDDP resistance.

Previously, it has been reported that target genes can be activated by activating the associated signaling pathway [44] or by directly activating the nuclear receptor [45]. NSCLC resistance studies have shown that RXR agonists are efficacious in reversing NSCLC resistance to gemcitabine and paclitaxel by blocking the amplification of specific drug resistance genes [46, 47], suggesting that RXR activity plays a role in mediating the resistance of NSCLC cells to certain drugs. Here, we first identified a novel signaling axis, consisting of the histone deacetylation enzyme (HDAC), the nuclear receptor, RXR, and the serine protease HtrA1, that were involved in the progression of CDDP resistance. In the parental and CDDPresistant cells, the overexpression of HDAC1 had just slightly regulatory effect alone on HtrA1 transcription. In addition, given pan-HDAC inhibitor could obviously upregulate the expression of HtrA1, whereas specific inhibitor could not done it, suggesting regulation of HtrA1 is dependent on the co-regulation of HDAC subtypes. Notably, HtrA1 activity was significantly increased when RXR $\alpha$ was overexpressed, indicating that RXR $\alpha$ transcriptional activates HtrA1. Furthermore, the compound DW22, which is an HDAC inhibitor and RXR agonist [33], increased HtrA1 activity in a concentration dependent manner. These results suggest that the upregulation of HtrA1 is dependent on HDAC and RXR regulation. A possible mechanistic explanation for this is that the inhibition of HDAC, which increased the likelihood of chromatin being in an open or relaxed conformation, increasing the accessibility of transcription factors to DNA, facilitated the binding of the transcription factor RXR to its specific target sites in the HtrA1 promoter. RXR can form homodimers or heterodimers with the protein, retinoic acid receptor (RAR), vitamin D receptor (VDR), thyroxin receptor (TR), peroxisome proliferatoractivated receptor (PPAR) and neuro-inducing receptor (NGFIB) [34]. These homo/heterodimers participate in signal transduction pathways that regulate processes such as cell proliferation, differentiation, metabolism and apoptosis [48, 49]. We incubated CDDP-resistant cells with the RXR homologous agonist, bexarotene and the heterologous agonists, pioglitazone (PPAR agonist), calcitriol (VDR agonist) and tamibarotene (RAR agonist) to determine if RXR regulation was dependent upon homodimeric or heterodimeric transcription complexes. Our results indicated that HtrA1 activity was significantly increased when bexarotene was used in combination the VDR and RAR agonists in RXR $\alpha$-overexpressing H1299/ CDDP cells. These results indicated that RXR is an important target for the regulation of HtrA1 gene transcription, and the activity of RXR is dependent on the formation of RXR:VDR and RXR:RAR heterodimers.

The rescue of tumor suppressor genes is one of the strategies for the treatment of cancerous tumors [50] Several methods for rescuing tumor suppressor genes have been reported, such as generating an overexpressor [51] and targeting apoptosis and necroptosis pathways [52]. However, these genetic intervention strategies are often problematic, and there have only been a few reports on the coordinated regulation of epigenetic enzymes and nuclear receptors. Therefore, we determined if CDDP resistance could be reversed by rescuing HtrA1. Our results indicated that the inhibition of HDAC and simultaneous activation of RXR increases the expression of HtrA1, thus increasing the response of CDDPresistant NSCLC cells to cisplatin and inhibiting the migration and invasion of CDDP-resistant cells. Furthermore, the inhibition of HDAC and simultaneous activation of RXR significantly enhanced the efficacy of cisplatin by increasing HtrA1 expression in CDDPresistant NSCLC xenograft tumors in vivo.

\section{Conclusion}

The findings of our study are summarized in a schematic diagram (Fig. 7). In CDDP-resistant NSCLC, HDAC and RXR synergistically regulate the expression of HtrA1. The inhibition of HDAC and simultaneous activation of RXR up-regulate HtrA1 expression, and this signaling axis is involved in mediating in vitro and in vivo resistance to cisplatin. Mechanistically, RXR $\alpha$ is an important transcriptional activator of HtrA1, and it activates HtrA1 transcription by forming heterodimers. The efficacy of CDDP was increased in CDDP-resistant cells by DW22, which by inhibiting HDAC and activating RXR, significantly decreased the invasion and migration of tumor cells and inhibited the growth of xenograft tumors, reversing cisplatin resistance. The results of this study reveal a new strategy to rescue a tumor suppressor gene, which may provide a breakthrough for the discovery of novel drugs that are efficacious in overcoming chemotherapeutic resistance.

\section{Methods \\ Cell culture}

The human NSCLC cell lines A549, NCI-H460 and NCI-H1299 (American Type Culture Collection, Manassas, VA, USA) were grown in RPMI 1640 medium (Gibco, USA), with $10 \%$ fetal bovine serum (Gibco, USA) and $1 \%$ penicillin-streptomycin (Gibco, USA) at $37^{\circ} \mathrm{C}$ in a $5 \% \mathrm{CO}_{2}$ incubator. The same cell lines with acquired cisplatin resistance, in brief, NCI-H460 and NCI-H1299 cells were induced by CDDP from $500 \mathrm{ng} /$ $\mathrm{ml}$ at the beginning and increased to $1500 \mathrm{ng} / \mathrm{ml}$ step by 


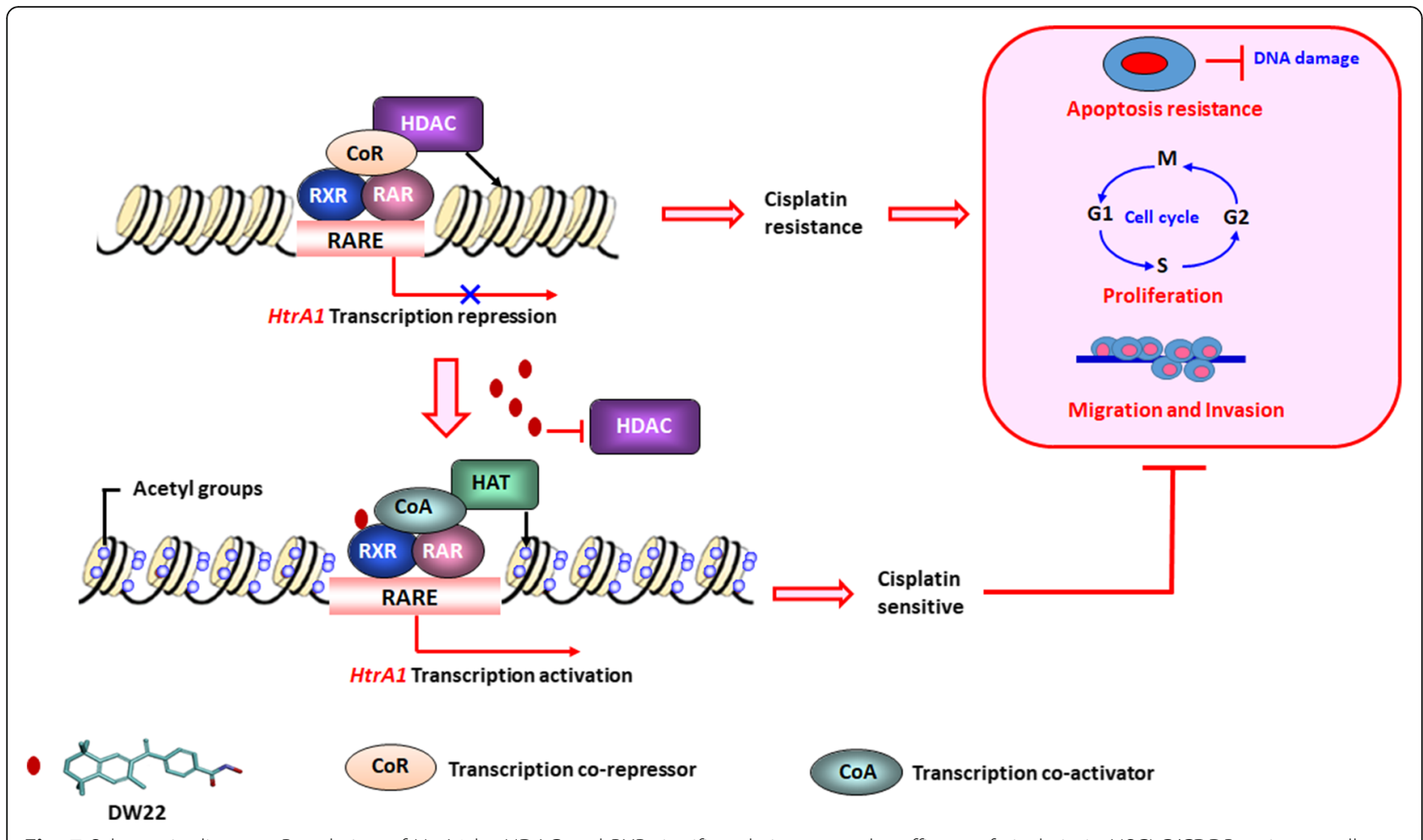

Fig. 7 Schematic diagram. Regulation of HtrA1 by HDAC and RXR significantly increases the efficacy of cisplatin in NSCLC/CDDP resistant cells

step until the RI value were enough to identify the resistance. The final $\mathrm{IC}_{50}$ and $\mathrm{RI}$ values were shown in supplementary Table 1. A549/CDDP (obtained from KeyGEN BioTECH, China), NCI-H460/CDDP and NCI-H1299/ CDDP (constructed in our lab), were maintained by continuous exposure to a medium containing $1000 \mathrm{ng} / \mathrm{ml}$ of CDDP for A549/CDDP and $1500 \mathrm{ng} / \mathrm{ml}$ of CDDP for NCI-H1299/CDDP and NCI-H460/CDDP.

\section{Compounds}

DW22 (MV: 340.68) was synthesized in our lab as previously described [35]. Cisplatin (CDDP), panobinostat (LBH-589), CG347B, and bexarotene were obtained from MedChem Express (Monmouth Junction, NJ, USA). Vorinostat (SAHA) was obtained from Sigma-Aldrich (St. Louis, MO, USA).

\section{Cell viability assay}

In vitro cell viability was determined using the MTT assay. Cells $\left(6 \times 10^{3} /\right.$ well $)$ were seeded in 96 -well culture plates. The cells were incubated with various concentrations of the test compounds for $72 \mathrm{~h}$ at $37^{\circ} \mathrm{C}$ in a $5 \%$ $\mathrm{CO}_{2}$ incubator, after which $10 \mu \mathrm{l}$ of the MTT solution $(5 \mathrm{mg} / \mathrm{ml})$ was added to each well, and the plates were incubated for an additional $4 \mathrm{~h}$ at $37^{\circ} \mathrm{C}$. Subsequently, $100 \mu \mathrm{l}$ of DMSO was added to each well and the optical density of each well was measured at $570 \mathrm{~nm}$ using a multi-mode plate reader (Molecular Devices, San Jose, CA, USA).

\section{Transwell invasion assays}

Cell invasion was assessed using Transwell Permeable Supports (Corning, NY, USA). The chemoattractant VEGF in the lower chambers consisted of $500 \mu \mathrm{l}$ of medium containing 10\% fetal bovine serum with different concentrations of the test compounds. Approximately $4 \times 10^{5}-1 \times 10^{6}$ cells $/ \mathrm{ml}$ were resuspended in $100 \mu \mathrm{l}$ serum-free medium and plated onto Transwell filter inserts coated with Matrigel 1:8 (BD Biosciences, Franklin Lakes, NJ, USA) for the invasion assay. Cells on the bottom side were fluorescently labelled with calcein$\mathrm{AM}$ and photographed using a ImageXpress-Micro high content system (Molecular Devices, San Jose, CA, USA).

\section{Real-time cell analysis (RTCA)}

The assays were performed with cell invasion migration plates that contained 16 modified Boyden chambers and detection of cell invasion using a xCELLigence Analyser System (ACEA Biosciences, San Diego, CA, USA). The experiments were conducted according to the manufacturer's instructions, with the membrane uncoated for migration assays. A chemotactic signal for cell migration was provided by inoculating 30,000-50,000 cells in the serum-free medium in the upper chamber and supplying $10 \%$ FBS in the lower chamber fetal bovine serum. 


\section{Western blotting}

Cell lysates were extracted in RIPA buffer (CST, Danvers, MA, USA) and protein separation was performed using electrophoresis in $8-10 \%$ arc-bis gels. The proteins were transferred onto polyvinylidene difluoride membranes by a transfer system (Bio-Rad, Hercules, California, USA). The membranes were incubated with the appropriate primary and secondary antibodies, and then reacted with ECL detection reagents (Thermo Fisher Scientific, Waltham, MA, USA) and incubated for several minutes in a dark room. All antibody information is shown in supplementary Table 2.

\section{Immunohistochemistry and TUNEL assay}

Clinical tissue samples were embedded in paraffin and antigen retrieval was performed. Following the blockade of endogenous peroxidase activity, the samples were incubated with the primary antibodies of interest and the appropriate secondary antibodies and reacted with DAB detection reagents. The immunoreactive staining of proteins in tumor tissue was scored by applying a semiquantitatively immunoreactive scoring (IRS) system. Category A documented the intensity of immunostaining as 0 (no immunostaining), 1 (weak immunostaining), 2 (moderate immunostaining), and 3 (strong immunostaining). Category B documented the percentage of immunoreactive tumor cells as 0 (none), 1 (<25\%), 2 (26$50 \%), 3(51-74 \%)$, and 4 (> 75\%). Multiplication of category A and B resulted in an IRS ranging from 0 to 12 for each tumor. The median value of the immunoreactive score was chosen as the cut-off criterion to dichotomize into high- and low-expression subgroups.

The TUNEL system (Roche, Basel, Switzerland) was used to detect apoptosis in tumor sections on slides according to the manufacturer's protocol. The TUNEL reaction solution was substituted with TdT-free solution to create a negative control. The sections were incubated for 10 min with DNase and visualized using DAB staining. Positive nuclei were identified basd on the presence of a brown color. The percentage of positive cells out of the total cells counted was calculated.

\section{RNA isolation and RT-PCR}

Total RNA was extracted using a Trizol Reagent (Thermo Fisher Scientific, USA) and cDNA was synthesized using a Revert Aid First Strand c DNA Synthesis Kit (Thermo Fisher Scientific, USA), according to the manufacturer's protocol. Quantitative RT-PCR analyses were performed in technical triplicates using a SYBR Green Supermix kit (Thermo Fisher Scientific, USA). The expression levels of HtrA1 were determined using the $2-\Delta \Delta \mathrm{Ct}$ method and normalized to the housekeeping genes $\beta$-actin or GAPDH. All primers sequences are shown in supplementary Table 3.

\section{Vectors and transfections}

The pcDNA plasmid was a gift from Professor Chio Oka (NARA Institute of Science and Technology, ikoma, Japan), the pCMX-hRXR- $\alpha$ and pBJ5-HDAC plasmids were a gift from Professor Makoto Makishima (Nihon University, Tokyo, Japan), and the pGL3-basic and phRL-tk plasmids were obtained from Yingrun Biotechnologies (Changsha, China). HDAC1, RXR $\alpha, \mathrm{HtrA} 1$ and control siRNA were obtained from Life Technologies (Waltham, MA, USA), RXR $\gamma$ siRNA was obtained from RIBOBIO (Guangzhou, China). Cells were transfected with plasmids using Lipofectamine 3000 (Thermo Fisher Scientific, Waltham, MA, USA) for $48 \mathrm{~h}$ and siRNA using Lipofectamine RNAi MAX (Thermo Fisher Scientific, Waltham, MA, USA) for $24 \mathrm{~h}$, followed by the next treatment.

\section{Luciferase reporter assay}

The activity of the HtrA1 promotor was determined using a dual-luciferase reporter assay system, according to the manufacturer's instructions (Promega, Madison, WI, USA). The four promoter regions (P1-P4) of the HtrA1 gene were cloned into the pGL3-basic vector.

The RXR $\alpha$ transcription factor binding sites were mutated based on a consensus nucleotide sequence in the HtrA1 P3 promoter. The resulting constructs are pGL3HtrA1-P3-mut1, mut2 and mut3.

The RXR $\alpha$ transcription factor binding sites were mutated based on a consensus nucleotide sequence in the HtrA1 P1 promoter. The resulting constructs are pGL3-HtrA1-P1-M1', M2', M3', M4', M5' and M6'. M1': - 732 - 751, M2': - 530 - 546, M3': - $425 \sim-$ 439, M4': $-7 \sim+16$, M5': both $-530 \sim-546$ and $425 \sim-439$, M6: $-732 \sim-751,-530 \sim-546$ and $425 \sim-439$.

\section{HDAC activity assay}

The in vitro HDAC activity assay for paired cell lines was performed with an HDAC fluorescent activity assay kit (BioVision, Milpitas, CA, USA) according to the manual in the kit.

\section{RXR activity assay}

The in vitro RXR activity assay was performed on paired cell lines using an RXR $\alpha$ reporter assay kit (Cayman Chemical, USA) based on the manual in the kit.

\section{Chromatin immunoprecipitation (ChIP)}

The interaction of the RXR $\alpha$ protein with the HtrA1 gene and influence of histone acetylation on HtrA1 promoter were analyzed using a ChIP kit (CST, Danvers, MA, USA) according to instruction manual provided by the manufacturer. Briefly, an $\mathrm{RXR} \alpha$ antibody or $\mathrm{H3ac} /$ H4ac antibody were used for immunoprecipitation. 
HtrA1 promoter primers were used to carry out RTPCR on DNA isolated from the ChIP experiment. After quantitative $\mathrm{PCR}$, the amplification products were analyzed using agarose gel electrophoresis.

\section{mRNA microarray}

Total RNA was extracted from H460, A549, H460/ CDDP and A549/CDDP cells using a Trizol reagent (Thermo Fisher Scientific, Waltham, MA, USA). RNA sequencing analysis was performed to identify the differentially expressed genes between the parental cells and CDDP-resistant cells. Gene Set Enrichment Analysis (GSEA) was used for further analysis to identify the relevant genes.

\section{In vivo tumor growth model}

NCI-H460 cells with a stable knockdown of HtrA1 were established by transfection with an sh-HtrA1 lentivirus. After confirmation by Western blot, $1 \times 10^{6}$ sh-HtrA1 and control cells were injected into the right flank of 6to 8-weekold male Balb/c-nu mice. Two weeks after the injections, mice were administered CDDP $(5 \mathrm{mg} / \mathrm{kg}$, once per week, intravenously) for three weeks. To establish the xenograft model of cisplatin-resistant lung cancer, $2 \times 10^{6}$ A549/CDDP or H460/CDDP cells in $0.2 \mathrm{ml}$ serum-free medium were injected into the right flank of 6- to 8-weekold male Balb/c-nu mice. When the average tumor volume reached $50-80 \mathrm{~mm}^{3}$, the mice were randomly divided into five treatment groups: control (saline only), CDDP ( $5 \mathrm{mg} / \mathrm{kg}$, once per week, intravenously), DW22 $(25 \mathrm{mg} / \mathrm{kg}$, twice per week, intravenously), SAHA+bexarotene+CDDP $(25 \mathrm{mg} / \mathrm{kg}$, twice per week, $30 \mathrm{mg} / \mathrm{kg}$, twice per week, $5 \mathrm{mg} / \mathrm{kg}$, once per week, interval more than $2 \mathrm{~h}$, intravenously) and DW $22+\mathrm{CDDP}$ $(25 \mathrm{mg} / \mathrm{kg}$, twice per week, $5 \mathrm{mg} / \mathrm{kg}$, once per week, interval more than $2 \mathrm{~h}$, intravenously). The tumor size was measured once every 2 days using a caliper (tumor volume $=1 / 2 \times$ shortest diameter ${ }^{2} \times$ longest diameter). The body weight was also recorded once every 2 days. The mice were sacrificed after 14 days and the tumors were excised and stored at $-80^{\circ} \mathrm{C}$ until analysis using the TUNEL assay and Western blotting. This protocol was approved by the Committee on the Ethics of Animal Experiments of the Shenyang Pharmaceutical University.

\section{Statistical analysis}

Each experiment was repeated at least three times and results were shown as the mean \pm SEM. The data were analyzed using Student's t-test (Independent-Sample T Test) and a One-Way ANOVA analysis of variance (ANOVA), followed by post hoc analysis using Dunnett, using SPSS V 20.0 software (SPSS Inc., USA). The a priori significance level was $p<0.05$.

\section{Supplementary information}

Supplementary information accompanies this paper at https://doi.org/10. 1186/s12943-020-01256-9.

Additional file 1: Supplementary Figure 1. The identification of HtrA1 as a cisplatin resistance-related gene in NSCLC. A-B The differential expression of genes in A A549 and A549/CDDP cells, B NCl-H1299 and NCI-H1299/CDDP cells by RT-PCR. C GSEA analysis of PPAR, RAR and acetyltransferase in A549/CDDP resistant cells. D The activity of HDAC and RXR in NCl-H1299/CDDP and NCl-H1299 cells. E The protein expression levels of the major isoforms of HDAC and RXR in NCl-H1299/CDDP and NCl-H1299 cells. F The protein expression of HtrA1 in CDDP resistant cells after SAHA and CG347B treatment. ${ }^{*} P<0.05,{ }^{* *} P<0.01,{ }^{* * *} P<0.001$, as compared to the parental group or ctrl group.

Additional file 2: Supplementary Figure 2 The downregulation of HtrA1 by HDAC and RXR increases the efficacy of cisplatin in NSCLC/ CDDP resistant cells. A RT-PCR analysis of HtrA1 mRNA in NCl-H1299/ CDDP cells transfected with HDAC1 or control siRNA. B RT-PCR analysis of HtrA1 mRNA levels in NCI-H1299/CDDP cells transfected with a RXRa overexpression or control plasmid. C, E RT-PCR analysis of HtrA1 in C CDDP resistant NSCLC cells and $\mathbf{E}$ parental NSCLC cells incubated with bexarotene, LBH-589 or bexarotene + LBH-589. D RT-PCR analysis of HtrA1 mRNA levels in parental NSCLC cells and CDDP resistant NSCLC cells incubated with bexarotene, SAHA or bexarotene + SAHA. F-G The protein expression of HtrA1 when silenced HDAC1, overexpressed RXRa and silenced HDAC1 and overexpressed RXRa simultaneously. $\mathbf{H}$ The mRNA expression of RXR isoforms when treated with SAHA and the mRNA expression of HDAC1 when treated with Bexa. I Cell migration assay in NCl-H1299 cells transfected with a HtrA1 or control siRNA. ${ }^{*} P<$ $0.05,{ }^{* *} P<0.01$, as compared to the control group or scram group or mock group.

Additional file 3: Supplementary Figure 3 The prognosis of single HtrA1 (A), or HtrA1 combined with HDAC1(B) in NSCLC cases from the ProgGENEV2 database.

Additional file 4: Supplementary Figure 4. Transcriptional activation of HtrA1 depends on RXRa heterodimeric complexes and HDAC activity. A, B Dual luciferase reporter assay for the transcriptional activity of four HtrA1 promoter fragments (P1-P4) in parental NSCLC cells. ${ }^{\#} P<0.05$, ${ }^{\# \# P} P<0.01$, as compared to the pGL3-HtrA1-P1 construct. C The sequencing traces of mutated RXRa binding sites of HtrA1 promoter P1.. D-E Luciferase activity elicited by the HtrA1 P3 promotor in parental NSCLC cells after $\mathbf{D}$ overexpression of HDAC1 and $\mathbf{E}$ overexpression of RXRa. F The structure of DW22. G Luciferase activity elicited by the HtrA1 P3 promotor in parental NSCLC cells when treated with Bexa, SAHA and DW22. H The ChIP assay for the combination of HtrA1 and RXRa in NCl-H460/CDDP cells when incubated with DW22, bexarotene and SAHA. I Luciferase activity elicited by the HtrA1 P3 promotor in parental NSCLC cells incubated with different heterodimer activators. J RT-PCR analysis of HtrA1 mRNA levels in parental and CDDP resistant NSCLC cells incubated with different heterodimer activators. $\mathbf{K}$ The protein expression of HtrA1 in NCl-H1299/ CDDP cells when incubated with different heterodimer activators. L Luciferase activity elicited by the HtrA1 promotor in NCI-H1299/CDDP cells incubated with bexarotene combined with different heterodimer activators. $\mathbf{M}$ The sequencing traces of mutated RXRa binding sites in the HtrA1 P3 promoter. The resulting constructs are $\mathrm{PGL} 3-\mathrm{HtrA1}-\mathrm{P} 3-\mathrm{mut1}$, mut2 and mut3. N Luciferase activity elicited by the HtrA1 P3 promotor constructs from $\mathbf{M}$, with mutations in the RXRa binding sequences. ${ }^{\circledR} P<0.05$, ${ }^{\&}{ }^{\&} P<$ 0.01 , \& \& ${ }^{2} p<0.001$, as compared with $\mathrm{PGL} 3-\mathrm{H}$ trA1-P3. O Luciferase activity elicited by the HtrA1 P3-mut2 promotor in parental NSCLC cells after incubation with SAHA, bexarotene, DW22 or SAHA + bexarotene. P The ChIP assay for the binding ability of promotor of HtrA1 with RXRa. ${ }^{\mathrm{P}}<<$ 0.05 , \#\# $\mathrm{P}<0.01$, as compared to the P1 group or P3 + RXRa group. ${ }^{\&} \mathrm{P}<$ 0.05 , as compared to the P3 + HDAC1 + RXRa group. ${ }^{*} \mathrm{P}<0.05,{ }^{* * *} \mathrm{P}<0.01$, ${ }^{* * *} \mathrm{P}<0.01$, as compared with the control group.

Additional file 5: Supplementary Figure 5 The dual-target compound, DW22, significantly inhibits the growth of cisplatin-resistant cells by regulating HtrA1mRNA expression. A MTT assay indicating the sensitivity of parental NSCLC cells following incubation with DW22, cisplatin and DW22 + cisplatin for $72 \mathrm{~h}$. DMSO was set as the control group that 
comparing to treatment groups. B The combination index for DW22 + cisplatin in parental NSCLC cell lines was calculated using the Calcusyn program. $\mathrm{Cl}<0.90$ indicates synergism, $0.90-1.10$ indicates an additive effect and $>1.10$ indicates antagonism. C Migration and invasion assays in parental and CDDP resistant NSCLC cells. D, E The inhibitory efficacy of DW22, bexarotene, SAHA or bexarotene + SAHA on $\mathbf{D}$ invasion and $\mathbf{E}$ migration in CDDP resistant NSCLC cells. $\mathbf{F}$, G The inhibitory efficacy of DW22, bexarotene, $\mathrm{LBH}-589$ or bexarotene $+\mathrm{LBH}-589$ on $\mathbf{F}$ invasion and G migration in A549/CDDP cells. $\mathbf{H}-\mathbf{I}$ The mRNA and protein expression of HtrA1 after DW22 treatment. ${ }^{*} P<0.05,{ }^{* * *} P<0.01,{ }^{* * *} P<0.001$ as compared with VEGF group or control group. ${ }^{\# \# P}<<0.001$ as compared to the SAHA group. ${ }^{\&} P<0.05,{ }^{\& \& \&} P<0.001$ as compared to the bexarotene group.

\section{Additional file 6: Supplementary Figure 6 DW22 signficantly} decreases cisplatin resistance in NSCLC by rescuing $\mathrm{HtrA} 1$ protein expression in vivo. A, B The effect of cisplatin, DW22 and cisplatin + DW22 on $\mathbf{A}$ tumor volume, tumor weight and $\mathbf{B}$ body weight in Balb/cnu mice with A549/CDDP xenografts. C The effect of cisplatin, DW22, SAHA + bexarotene + CDDP and cisplatin + DW22 on the viscera index in Balb/c-nu mice with $\mathrm{NCl}-\mathrm{H} 460 / \mathrm{CDDP}$ xenografts. D The apoptosis proteins in A549/CDDP tumor tissues treated with CDDP, DW22 and CDDP + DW22. Four tumor tissues from four independent mice in each group were used for this analysis. Every two of them were mixed together randomly that shown as \#1 and \#2. E The protein expression level of HtrA1 and Acetylated Histone4 in NCl-H460/CDDP xenograft tumor tissues. " $\mathrm{P}<$ $0.05,{ }^{* * *} \mathrm{P}<0.01,{ }^{* * * *} \mathrm{P}<0.001$, as compared to the control group.

Additional file 7: Supplementary Table 1. The $I_{50}$ values and RI values of NSCLC parental cells and CDDP resistant cells for $72 \mathrm{~h}$. Supplementary Table 2 Antibody information. Supplementary Table 3 Primer Sequences

\section{Abbreviations}

NSCLC: Non-small-cell lung carcinoma; CDDP: Cisplatin; HDAC: Histone deacetylases; RXR: Retinoid X receptor; RTCA: Real time cellular analysis

\section{Acknowledgements}

We thank Dr. Makoto Makishima (Nihon University) and Dr. Chio Oka (NARA Institute of Science and Technology) for providing plasmids.

\section{Authors' contributions}

LW, ZC and CW conceived the study. WW, MZ, LC, YR, JZ (Jingyuan), and JC acquired samples and performed the experiments and data analyses. $\sqcup, J Z$ (Jiayu), JY, and GC analyzed and interpreted the data. WW, LW, ZC and CA wrote and revised the manuscript. All authors read and approved the final manuscript.

\section{Funding}

This work was supported by the National Natural Science Foundation of China (No. 81572947, 81773216, 81773780), the "Xingliao Talents" Program of Liaoning Province (No. XLYC1902008), and the Youth Science and Technology Innovation Leader Program of Shenyang (No. RC190457).

\section{Ethics approval and consent to participate}

All animal studies were reviewed and approved by the laboratory animal unit of Shenyang Pharmaceutical University.

\section{Competing interests}

The authors declare that they have no competing interests.

\section{Author details}

'Department of Pharmacology, Shenyang Pharmaceutical University, Shenyang, PR China. ${ }^{2}$ Benxi Institute of Pharmaceutical Research, Shenyang Pharmaceutical University, Shenyang, PR China. ${ }^{3}$ Department of Pathology, Wuhan General Hospital of Chinese People's Liberation Army, Wuhan, PR China. ${ }^{4}$ Key Laboratory of Structure-Based Drugs Design and Discovery of Ministry of Education, Shenyang Pharmaceutical University, Shenyang, PR China. ${ }^{5}$ Department of Pharmaceutical Sciences, College of Pharmacy and Health Sciences, St. John's University, Newyork, NY 11439, USA.
Received: 21 April 2020 Accepted: 25 August 2020

Published online: 02 September 2020

\section{References}

1. Siegel RL, Miller KD, Jemal A. Cancer statistics, 2019. CA Cancer J Clin. 2019; 69(1):7-34.

2. Sun R, Liu Z, Wang L, Lv W, Liu J, Ding C, et al. Overexpression of stathmin is resistant to paclitaxel treatment in patients with non-small cell lung cancer. Tumour Biol. 2015:36(9):7195-204.

3. Hirsch FR, Scagliotti GV, Mulshine JL, Kwon R, Curran WJ Jr, Wu YL, et al. Lung cancer: current therapies and new targeted treatments. Lancet (London, England). 2017;389(10066):299-311.

4. Kunkeaw N, Lee YS, Im WR, Jang JJ, Song MJ, Yang B, et al. Mechanism mediated by a noncoding RNA, nc886, in the cytotoxicity of a DNA-reactive compound. Proc Nat Acad Sci USA. 2019;116(17):8289-94.

5. Siegel RL, Miller KD, Jemal A. Cancer Statistics, 2017. CA Cancer J Clin. 2017; 67(1):7-30.

6. Baudino TA, Cleveland JL. The Max network gone mad. Mol Cell Biol. 2001; 21(3):691-702.

7. Siddik ZH. Cisplatin: mode of cytotoxic action and molecular basis of resistance. Oncogene. 2003;22(47):7265-79.

8. Dasari S, Tchounwou PB. Cisplatin in cancer therapy: molecular mechanisms of action. European J pharmacol. 2014;740:364-78.

9. O'Byrne KJ, Barr MP, Gray SG. The role of epigenetics in resistance to Cisplatin chemotherapy in lung cancer. Cancers. 2011;3(1):1426-53.

10. More SS, Akil O, lanculescu AG, Geier EG, Lustig LR, Giacomini KM. Role of the copper transporter, CTR1, in platinum-induced ototoxicity. J Neurosci. 2010;30(28):9500-9.

11. Galluzzi L, Vitale I, Michels J, Brenner C, Szabadkai G, Harel-Bellan A, et al. Systems biology of cisplatin resistance: past, present and future. Cell Death Dis. 2014;5(5):e1257.

12. Fong WF, Wang C, Zhu GY, Leung CH, Yang MS, Cheung HY. Reversal of multidrug resistance in cancer cells by Rhizoma Alismatis extract. Phytomedicine. 2007;14(2-3):160-5.

13. Chen ZS, Kawabe T, Ono M, Aoki S, Sumizawa T, Furukawa T, et al. Effect of multidrug resistance-reversing agents on transporting activity of human canalicular multispecific organic anion transporter. Mol Pharmacol. 1999; 56(6):1219-28

14. Fujii R, Mutoh M, Sumizawa T, Chen ZS, Yoshimura A, Akiyama S. Adenosine triphosphate-dependent transport of leukotriene $C 4$ by membrane vesicles prepared from cisplatin-resistant human epidermoid carcinoma tumor cells. J Nat Cancer Institute. 1994;86(23):1781-4.

15. Gentile F, Tuszynski JA, Barakat KH. New design of nucleotide excision repair (NER) inhibitors for combination cancer therapy. J Mol Graphics Modelling. 2016;65:71-82.

16. Liu JL, Wang Y, Jiang J, Kong R, Yang YM, Ji HF, et al. Inhibition of survivin expression and mechanisms of reversing drug-resistance of human lung adenocarcinoma cells by siRNA. Chinese Med J. 2010;123(20):2901-7.

17. Qu Y, Xia P, Zhang S, Pan S, Zhao J. Silencing XIAP suppresses osteosarcoma cell growth, and enhances the sensitivity of osteosarcoma cells to doxorubicin and cisplatin. Oncol Rep. 2015;33(3):1177-84.

18. Galluzzi L, Senovilla L, Vitale I, Michels J, Martins I, Kepp O, et al. Molecular mechanisms of cisplatin resistance. Oncogene. 2012;31(15):1869-83.

19. Chan D, Zhou Y, Chui CH, Lam KH, Law S, Chan AS, et al. Expression of Insulin-Like Growth Factor Binding Protein-5 (IGFBP5) Reverses CisplatinResistance in Esophageal Carcinoma. Cells. 2018;7(10):143-58.

20. Sen T, Tong P, Stewart CA, Cristea S, Valliani A, Shames DS, et al. CHK Inhibition in Small-Cell Lung Cancer Produces Single-Agent Activity in Biomarker-Defined Disease Subsets and Combination Activity with Cisplatin or Olaparib. Cancer Res, 2017:77(14):3870-84.

21. Socinski MA, Jotte RM, Cappuzzo F, Orlandi F, Stroyakovskiy D, Nogami N, et al. Atezolizumab for First-Line Treatment of Metastatic Nonsquamous NSCLC. N Engl J Med. 2018;378(24):2288-301.

22. Frochaux V, Hildebrand D, Talke A, Linscheid MW, Schlüter H. Alpha-1antitrypsin: a novel human high temperature requirement protease $\mathrm{A} 1$ (HTRA1) substrate in human placental tissue. PloS one. 2014;9(10):e109483.

23. Campioni M, Severino A, Manente L, Tuduce IL, Toldo S, Caraglia M, et al. The serine protease HtrA1 specifically interacts and degrades the tuberous sclerosis complex 2 protein. Mol Cancer Res. 2010;8(9):1248-60.

24. Xiong Z, Fu Z, Shi J, Jiang X, Wan H. HtrA1 Down-regulation Induces Cisplatin Resistance in Colon Cancer by Increasing XIAP and Activating PI3KJAkt Pathway. Ann clin lab Sci. 2017;47(3):264-70. 
25. Wang N, Eckert KA, Zomorrodi AR, Xin P, Pan W, Shearer DA, et al. Downregulation of HtrA1 activates the epithelial-mesenchymal transition and ATM DNA damage response pathways. PloS one. 2012;7(6):e39446.

26. Zurawa-Janicka D, Skorko-Glonek J, Lipinska B. HtrA proteins as targets in therapy of cancer and other diseases. Exp Opin Therapeutic targets. 2010; 14(7):665-79.

27. Ikushima H, Miyazono K. TGFbeta signalling: a complex web in cancer progression. Nature Rev Cancer. 2010;10(6):415-24

28. Oka C, Tsujimoto R, Kajikawa M, Koshiba-Takeuchi K, Ina J, Yano M, et al. HtrA1 serine protease inhibits signaling mediated by Tgfbeta family proteins. Development (Cambridge, England). 2004;131(5):1041-53.

29. Chien J, Aletti G, Baldi A, Catalano V, Muretto P, Keeney GL, et al. Serine protease HtrA1 modulates chemotherapy-induced cytotoxicity. J Clin Invest. 2006;116(7):1994-2004

30. He X, Khurana A, Maguire JL, Chien J, Shridhar V. HtrA1 sensitizes ovarian cancer cells to cisplatin-induced cytotoxicity by targeting XIAP for degradation. Int J Cancer. 2012;130(5):1029-35.

31. Simpson CD, Anyiwe K, Schimmer AD. Anoikis resistance and tumor metastasis. Cancer Lett. 2008;272(2):177-85.

32. Skorko-Glonek J, Zurawa-Janicka D, Koper T, Jarzab M, Figaj D, Glaza P, et al. HtrA protease family as therapeutic targets. Curr Pharmaceutical Design. 2013;19(6):977-1009.

33. Xu Y, Jiang Z, Zhang Z, Sun N, Zhang $M$, Xie J, et al. HtrA1 downregulation induces cisplatin resistance in lung adenocarcinoma by promoting cancer stem cell-like properties. J Cell Biochem. 2014;115(6):1112-21.

34. IJ A, Tan NS, Gelman L, Kersten S, Seydoux J, Xu J, et al. In vivo activation of PPAR target genes by RXR homodimers. EMBO J. 2004;23(10):2083-91.

35. Wang L, Chen G, Chen K, Ren Y, Li H, Jiang X, et al. Dual targeting of retinoid $X$ receptor and histone deacetylase with DW22 as a novel antitumor approach. Oncotarget. 2015;6(12):9740-55.

36. Schmidt N, Irle I, Ripkens K, Lux V, Nelles J, Johannes C, et al. Epigenetic silencing of serine protease HTRA1 drives polyploidy. BMC cancer. 2016;16: 399.

37. Mi W, Guan H, Lyu J, Zhao D, Xi Y, Jiang S, et al. YEATS2 links histone acetylation to tumorigenesis of non-small cell lung cancer. Nat Commun. 2017:8(1):1088

38. Witt O, Deubzer HE, Milde T, Oehme I. HDAC family: What are the cancer relevant targets? Cancer Lett. 2009;277(1):8-21.

39. Wang L, Li H, Ren Y, Zou S, Fang W, Jiang $X$, et al. Targeting HDAC with a novel inhibitor effectively reverses paclitaxel resistance in non-small cell lung cancer via multiple mechanisms. Cell Death Dis. 2016;7:e2063.

40. Wang L, Liu X, Ren Y, Zhang J, Chen J, Zhou W, et al. Cisplatin-enriching cancer stem cells confer multidrug resistance in non-small cell lung cancer via enhancing TRIB1/HDAC activity. Cell Death Dis. 2017:8(4):e2746.

41. Huffman K, Martinez ED. Pre-clinical studies of epigenetic therapies targeting histone modifiers in lung cancer. Front Oncol. 2013;3:235.

42. Zuco V, Cassinelli G, Cossa G, Gatti L, Favini E, Tortoreto M, et al. Targeting the invasive phenotype of cisplatin-resistant non-small cell lung cancer cells by a novel histone deacetylase inhibitor. Biochem Pharmacol. 2015;94(2):7990.

43. Perego P, Zuco V, Gatti L, Zunino F. Sensitization of tumor cells by targeting histone deacetylases. Biochem Pharmacol. 2012;83(8):987-94.

44. Wang LH, Jiang XR, Chen GL, Guo W, Zhang JY, Cui LJ, et al. Anti-tumor activity of SL4 against breast cancer cells: induction of G2/M arrest through modulation of the MAPK-dependent p21 signaling pathway. Scientific Rep. 2016;6:36486.

45. Hansen NJ, Wylie RC, Phipps SM, Love WK, Andrews LG, Tollefsbol TO. The low-toxicity 9-cis UAB30 novel retinoid down-regulates the DNA methyltransferases and has anti-telomerase activity in human breast cancer cells. Int J Oncol. 2007;30(3):641-50.

46. Tooker P, Yen WC, Ng SC, Negro-Vilar A, Hermann TW. Bexarotene (LGD1069, Targretin), a selective retinoid $X$ receptor agonist, prevents and reverses gemcitabine resistance in NSCLC cells by modulating gene amplification. Cancer Res. 2007;67(9):4425-33.

47. Yen WC, Corpuz MR, Prudente RY, Cooke TA, Bissonnette RP, Negro-Vilar A et al. A selective retinoid $X$ receptor agonist bexarotene (Targretin) prevents and overcomes acquired paclitaxel (Taxol) resistance in human non-small cell lung cancer. Clin Cancer Res. 2004;10(24):8656-64.

48. Willson TM, Brown PJ, Sternbach DD, Henke BR. The PPARs: from orphan receptors to drug discovery. J Med Chem. 2000;43(4):527-50.
49. Dawson MI, Xia Z. The retinoid X receptors and their ligands. Biochimica et biophysica acta. 2012;1821(1):21-56.

50. Blandino G, Di Agostino S. New therapeutic strategies to treat human cancers expressing mutant p53 proteins. J Exp Clin Cancer Res. 2018;37(1):30.

51. Lusche DF, Buchele EC, Russell KB, Soll BA, Vitolo MI, Klemme MR, et al. Overexpressing TPTE2 (TPIP), a homolog of the human tumor suppressor gene PTEN, rescues the abnormal phenotype of the PTEN(-/-) mutant. Oncotarget. 2018;9(30):21100-21.

52. Dasgupta A, Nomura M, Shuck R, Yustein J. Cancer's Achilles' Heel: Apoptosis and Necroptosis to the Rescue. Int J Mol Sci. 2016;18(1):23-43.

\section{Publisher's Note}

Springer Nature remains neutral with regard to jurisdictional claims in published maps and institutional affiliations.
Ready to submit your research? Choose BMC and benefit from:

- fast, convenient online submission

- thorough peer review by experienced researchers in your field

- rapid publication on acceptance

- support for research data, including large and complex data types

- gold Open Access which fosters wider collaboration and increased citations

- maximum visibility for your research: over $100 \mathrm{M}$ website views per year

At BMC, research is always in progress.

Learn more biomedcentral.com/submissions 